\title{
Dynamic Linkages between Brics and Other Emerging Equity Markets
}

\author{
Sanjay Sehgal' ${ }^{1}$ Arjun Mittal1,2* ${ }^{*}$ Anand Mittal $^{3}$ \\ ${ }^{1}$ Department of Financial Studies, University of Delhi, Delhi, India \\ ${ }^{2}$ Shri Ram College of Commerce, University of Delhi, Delhi, India \\ ${ }^{3}$ Hansraj College, University of Delhi, Delhi, India \\ Email: sanjayfin15@yahoo.co.in, *arjunmittal@ymail.com,dr.anandmittal@yahoo.com
}

How to cite this paper: Sehgal, S., Mittal, A. and Mittal, A. (2019) Dynamic Linkages between Brics and Other Emerging Equity Markets. Theoretical Economics Letters, 9, 2636-2666.

https://doi.org/10.4236/tel.2019.97166

Received: August 5, 2019

Accepted: August 28, 2019

Published: August 31, 2019

Copyright $\odot 2019$ by author(s) and Scientific Research Publishing Inc. This work is licensed under the Creative Commons Attribution International License (CC BY 4.0).

http://creativecommons.org/licenses/by/4.0/

\section{(c) (i) Open Access}

\begin{abstract}
In this paper, we analyze dynamic interactions between stock markets of BRICS (Brazil, Russia, India, China and South Africa) and other select emerging economies as classified by IMF [1] from January 2001 to June 2017. We employ ADCC-EGARCH model as well as block aggregation technique as suggested by Diebold-Yilmaz [2] framework and order-invariance of GVDs (Generalized Variance Decompositions) as developed by Greenwood-Nimmo, Nguyen, \& Rafferty [3] to examine return and risk spillovers within as well as across the BRICS and other sample Emerging Market Economies (EMEs). The results suggest the cohesiveness within BRICS equity markets is moderate. Our results also show increased integration amongst BRICS economies during the global financial crisis period, implying the presence of Contagion effect. Furthermore, Mexico, Chile, Hungary, Turkey and Poland seem to be good candidates to be included along with BRICS for forming a larger Emerging market economic block. This expanded block will not only ensure strengthening trade and financial ties among the participating countries, but also provide a better balance between the emerging and the developed world. This paper contributes immensely to the literature on international finance dealing with financial integration, particularly for emerging markets. The study provides important implications for global policy makers, international economic agencies, investors and the academic community.
\end{abstract}

\section{Keywords}

BRICS, EMEs, Return-Spillovers, Volatility-Spillovers, ADCC, Diebold-Yilmaz

\section{Introduction}

Economic liberalization during the 1980s and 1990s of most of the underdeve- 
loped/developing nations led to enhanced integration of financial markets that paved the way to increased international capital flows. Financial integration is the degree to which financial markets of one country is connected to another which can be at local, regional or at international level [4] [5] [6]. The frontier economies of the developing world provide risk diversification opportunities along with attractive returns as compared to the developed economies to global equity investors. The equity markets offer access to the rapidly growing sectors of the emerging economies that have benefits of larger demand creation from the increasing consumption requirements. Evidence from MSCI Emerging market index provides that in recent decades, the markets have performed much better than the world markets. After the Asian crisis of 1997-1998 and the Global Financial Crisis (GFC) of 2008-2009, integration and linkages in the developing world have been of key interest to many researchers and policy makers as it may have important implications in diversification opportunities for portfolio investors and to frame macroeconomic policies to ensure stability. The GFC has altered the dynamics by causing contagion around the globe. Some emerging economies have remained insulated initially with some effect realized later. The emerging economies' high demand helped the developed world in some way to be bailed out of the crisis.

An emerging market economy (EME) is a country having some characteristics $^{1}$ of an advanced/developed market, but fails to meet all standards to be a developed market [7]. This may include countries that were developed markets earlier or have the future potential to be developed markets. Emerging markets now account for $60 \%$ of the global GDP and contribute to over $80 \%$ of the global economic growth after the financial crisis of 2008 [8]. Emerging economies are now regarded as the engines of global growth. The characteristics of emerging markets have now also been redefined with economic development and inter-connectedness of financial markets [7]. The concept of economic integration is typically based on economic cooperation among neighbouring countries or countries within the same continent often referred to as natural partners. Transaction costs have been reduced drastically by technological progress, intercontinental and integration has become more and more important in the current era of globalization [9]. BRICS as an economic block is an outcome of such a process. Jim O'Neill from Goldman Sachs in 2001 in a paper entitled "Building Better Global Economic BRICs" coined the acronym BRIC. This acronym has been widely used as a mark of an apparent shift in economic power globally from the developed economies towards the developing world [10]. Projections of the future power of the BRIC economies vary widely. Some sources suggest that they might overtake the G7 economies by 2027. BRIC countries have the economic capabilities to become the four top dominant economies by 2050. In 2010, ${ }^{1}$ Characteristics of Emerging Economies as per Morgan Stanley Capital International (MSCI) include: 1) Transitional Economy: Moving from closed economy to open economy market; 2) Young and Growing population; 3) Pressure on Developing Infrastructure; 4) Increasing Foreign Investment. 
South Africa was included as a BRIC nation. Trade linkages ${ }^{2}$ exist between BRIC and South Africa; however, the intensity of linkages varies across countries. South Africa's real output and imports are considerably impacted by shocks from all BRIC nations. South Africa and Russia are highly linked to China, whereas India and Brazil have linkages of moderate intensity with China [11] [12]. BRICS together hold only eleven percent of total IMF voting rights, The World Bank is traditionally headed by Americans, and IMF by Europeans. Some experts believe that establishment of New Development Bank (NDB) by BRICS, Emergency Reserve Fund, along with Asian Infrastructure Investment Bank (AIIB) provide a viable alternative to the developing world, for funding apart from the World Bank and the IMF, keeping a check to their growing monopoly power [13] [14].

To ensure capital market integration it is inevitable to develop the capital markets, ensure consistency and connected markets with adequate infrastructure by reducing costs to ensure increased cross border trade and an increase in international investments of global financial instruments causing improved savings and investments. Capital account liberalization is important to ensure financial integration and it promotes flow of capital from surplus countries to the deficient ones [15]. Sehgal, Pandey, \& Deisting [16] have suggested fiscal position, external position and governance among the Macroeconomic factors, stock market performance among the Market-related factors and trade linkages among the Trade factors as the fundamental drivers of equity market integration of the East Asian Economic Community region. The study has been made taking some of the advanced economies of Asia and Pacific. BRICS specifically is an economic group and not a regional group. Its members are characterized by heterogeneous political, economic and social structures. In the last two decades, equity markets of almost all the members of BRICS have seen tremendous rise, much higher than the developed markets. The move towards liberalization and opening of the markets has caused increased flow of capital and introduction of a wide variety of financing instruments with options available to domestic investors to invest/raise capital abroad. Visalakshmi \& Lakshmi [17] point out the increase in growth of BRICS in the past decade has impacted capitalization of the stock markets along with dependence with other equity markets. The correlation between the developed and the emerging markets is low which has encouraged international investors to invest around the globe and exploit the benefits of diversification opportunities. The fast pace of advancement of the emerging markets has paved a way of these markets to be industrialized economies in the near future. Lately, there has been an increase in cross listed firms in financial centers across BRICS. Cross-listing ensures informational efficient environment thereby reducing the cost of capital. American Depositary Receipts (ADRs) is one of the methods of cross listing which permits companies in BRICS to trade shares in the US capital market. Closely linked equity markets may have ${ }^{2}$ Trade Linkages refers to the degree, direction and intensity of trade of South Africa with BRIC Countries. 
serious spillover implications for others.

This recent slowdown of the BRICS has changed its internal cohesiveness and with other EMEs. BRICS interaction with other emerging economies may provide some vital insights about potential entrants into this economic block in future. It may be interesting to study how this economic block and the economic/trade integration among BRICS and with other developing economies affect the internal cohesiveness. This may further strengthen integration in this block and bring positive effects in its trade, financial integration and policy coordination within the group and off the group with other emerging economies. Thus, this paper examines dynamic co-movements for BRICS stock markets and other select EMEs through price-based measures of financial integration.

The rest of this paper is framed as follows: Section 2 provides a brief review of literature. Section 3 describes the data along with its properties. Section 4 describes the methodological framework adopted. Section 5 provides the empirical results and Section 6 summarizes the conclusions and suggests policy implications. Tables and Figures are also presented at the end of the paper.

\section{Literature Review}

International stakeholders have shown great interests in the dynamic relationships between returns and volatilities in the emerging markets. Thus, there is a considerable research and literature in this area focusing on economic interaction between emerging economies including BRICS.

Bhar \& Nikolova [18] examine the level of integration and the dynamic relationship between the BRIC countries, their respective regional economies and the world. It is found that India exhibits the highest global and regional integration among the BRIC countries, which is followed in the order Brazil, Russia and China. Sheu \& Liao [19] demonstrate both long-run time-varying nonlinear cointegration relationships and short-run time-varying Granger-causality relationships pertaining between the equity markets of US and each of the BRIC countries with these relationships altered in the financial crisis related to subprime mortgage in the short-run. Xu \& Hamori [20] indicate that the international transmission of equity prices between the BRICs and US weakened in both mean and variance due to 2008-2009 US financial crisis. Ahmad, Sehgal, \& Bhanumurthy [21] indicate that among GIPSI ${ }^{3}$ countries, Ireland, Italy and Spain appear to be more contagious for BRIICKS (Brazil, Russia, India, Indonesia, China, South Korea and South Africa) markets compared to Greece. The study reports that BRICS are severely affected by the contagion (shock) during the Eurozone crisis. Gabriela, Panait, \& Voica [22] analyze the importance of the BRICS group as representative of emerging countries in the world economy and conclude that each BRIC country has limited power and strengthening cooperation is a requirement to grow with each other in the world after crisis. Chen \& Lombaerde [23] propose indicators to assess the interdependence between the ${ }^{3}$ GIPSI Countries: Greece, Italy, Portugal, Spain and Ireland. 
BRIC economies and the economies of their respective "regions". Model estimations reveal that relative globalization of BRIC countries is linked to factors like; larger global sourcing from them, more asymmetry, enhanced regional competitiveness and trade dependence of BRIC's from the view of regional trade partners. Gilenko \& Fedorova [24] suggest that the linkages between the developed and the emerging BRIC stock markets have significantly changed after the crisis supporting the "decoupling" phenomenon. Jawadi, Mallick, \& Sousa [25] assess the macroeconomic impact of monetary and fiscal policy shocks for BRICS. Their study supports that an accommodative monetary as well as fiscal policy, is critical for both political and economic decision making. Syriopoulos, Makram, \& Boubaker [26] indicate that past own volatility is a critical factor in determining future volatility. The findings confirm earlier evidence of high regional as well as high global integration and more persistent dependency of Brazil and Russia (rather than of China and India) on the US. Nashier [27] findings supported short-term static as well as long-term dynamic integration among BRICS equity markets. Kan [28] found that other than China, BRICS countries generally have been affected by the contagion effect of the 2008-2009 financial crisis shedding light on the decoupling recoupling theory. Singh \& Singh [29] attempt to capture long run and short run inter-linkages along with causal relationships between the US and BRIC stock markets in the pre-crisis, during-crisis and post-crisis periods. The results report changing market dynamics and partial integration across the years 2004-2014. Robbani, Talukdar, \& Jain [30] suggest that US equity market has a significant mean return along with volatility spillover effects on BRICS equity markets. Mensi, Hammoudeh, \& Hoon [31] study dynamic correlations and diversification of portfolios between BRICS and major developed equity markets revealing a significant variability in time varying conditional correlations between these markets during the periods of upturns and downturns. Bonga-Bonga [32] assesses the intensity of financial shock transmission among South Africa and BRICS members grouping to infer the extent of contagion for the period of 1996 to 2012. They conclude that South Africa is affected more by crises/shocks originating from India, China and Russia, whereas these economies are minimally affected by crises/shocks from South Africa.

Further, there has been enormous literature related to integration in stock markets and regional groups around the world. For NAFTA (North American Free Trade Area) see [33] [34] [35], MENA (Middle East and North Africa Region) see [36] [37] [38], Europe see [39]-[43] are among some papers that study linkages in regional groups. Literature on BRICS has seen growth in the past decade especially after the GFC. Studies have found mixed results regarding the degree of integration in BRICS markets and with the developed world. Financial integration/Information transmission/Information linkages in this study shall be measured by return and volatility spillover. Since signals from one market, transmit, link, or spill over to the other through return as well as volatility in one or both markets, it is termed information spillover/transmission/linkages. BRICS 
as an economic block should exhibit high association with other emerging economies. Integration shall help in assessing the increasing economic power of BRICS

The literature review shows that there has been active research undertaken to study the BRICS economies, this study fills important gaps in the available existing literature in the following ways: 1) The existing studies on BRICS made so far have limited scope. Apart from ADCC, this paper has widened its scope by utilizing the block aggregation technique under the Diebold-Yilmaz framework enhanced by Greenwood-Nimmo et al. [3] to examine return and risk spillovers within as well as across the BRICS and other sample Emerging Market Economies (EMEs). This technique here is relatively new and not used extensively in the literature; 2) Research on how integration varies in pre, during and post crisis periods is also scanty so far. This is necessary to capture the dynamics of integration; 3) Most existing studies cover only BRICS economies. This paper comprehensively studies integration for the entire set of 20 emerging market economies including BRICS since Jan 2001 to June 2017.

\section{Data}

Various sources provide a list of "Emerging Markets". However, one of the most used sources by researchers is the list published by the IMF, which includes Argentina, Bangladesh, Brazil, Bulgaria, Chile, China, Colombia, Hungary, India, Indonesia, Malaysia, Mexico, Pakistan, Peru, Philippines, Poland, Romania, Russia, South Africa, Thailand, Turkey, Ukraine and Venezuela [1].

The data comprises of daily values of stock price indices for the stated markets from $1^{\text {st }}$ Jan, 2001 to $30^{\text {th }}$ June 2017. The starting date of the data has been chosen from the year the term "BRIC" was coined in the paper "Building Better Global Economic BRICs"-Goldman Sachs Economic Research Group [10]. MSCI indices for all the countries have been obtained. They are composed of stocks which broadly represent stock composition in different countries. These are value-weighted free float-adjusted market capitalization indices, calculated with dividend re-investment. In the absence of MSCI index, national stock indices for Bangladesh (DSE 30, Dhaka Stock Exchange), Bulgaria (Bulgaria Stock Exchange Sofix Index, SOFIX), Romania (Bucharest Exchange Trading Index, BET), Ukraine (Ukraine $U X$ Index $U A X$ ) and Venezuela (Caracas Stock Exchange, IBC Index) have been obtained. However Bangladesh, Ukraine and Venezuela have been excluded from the study due to lack of availability of sufficient data. The data source is Thomson Reuters Eikon. We finally cover 20 emerging markets including BRICS. The returns of the local equity indices have been impacted by local currency movements against the US dollar. All the price indices are denominated in local currency to capture the true market movements. As supported by prior research, MSCI USA has been included as a proxy for global factors [16] [41]. Our sample markets lie in various time zones; hence they exhibit non-synchronous trading hours. Many studies have used weekly/monthly data 
sets [18] [44] [45] [46] to deal with non-synchronous trading bias. However, in an information-driven stock markets, information transmission [47] is much more frequent than monthly or weekly. Hence there exists a need to work with daily data to capture dynamic market movements. Following Forbes \& Rigobon [48] to check the problem of non-synchronous trading bias, we use the two-day average returns, Daily returns are calculated as the first difference of log transformed price index series. The non-trading days vary across the indices because of difference in holidays. The value of index on such days or the day on which data is unavailable due to any other technical reason is presumed to remain the same, equal to its closing value on the last trading day before such day. Table 1 provides the information regarding economic growth and market characteristics for the sample economies. China has the highest GDP both as per current prices and PPP valuation and Bulgaria has the lowest. South Africa markets have the highest Market Capitalization as a percent of GDP. While the highest Value of Stock traded as a percent of GDP is observed for China. Chi-

Table 1. Economic and market characteristics of sample countries.

\begin{tabular}{|c|c|c|c|c|c|c|c|}
\hline S.No & Countries & $\begin{array}{c}\text { Short Name Used } \\
\text { in the Paper }\end{array}$ & $\begin{array}{l}\text { GDP in Billion } \\
\text { (Current US\$) }\end{array}$ & $\begin{array}{l}\text { GDP Growth } \\
\text { (Annual \%) }\end{array}$ & $\begin{array}{l}\text { GDP Per Capita } \\
\text { (Current US\$) }\end{array}$ & $\begin{array}{c}\text { Market Capitalization } \\
\text { of Listed Domestic } \\
\text { Companies (\% of GDP) }\end{array}$ & $\begin{array}{l}\text { Stocks Traded, } \\
\text { Total Value } \\
\text { (\% of GDP) }\end{array}$ \\
\hline 1 & Argentina & $\mathrm{AR}$ & 545.48 & -2.25 & $12,440.32$ & 11.66 & 0.80 \\
\hline 2 & Brazil & $\mathrm{BR}$ & 1796.19 & -3.59 & 8649.95 & 42.23 & 31.24 \\
\hline 3 & Bulgaria & BG & 53.24 & 3.94 & 7469.03 & $9.68^{\wedge}$ & $0.69^{*}$ \\
\hline 4 & Chile & CL & 247.03 & 1.59 & $13,792.93$ & 86.01 & 9.70 \\
\hline 5 & China & $\mathrm{CN}$ & $11,199.15$ & 6.69 & 8123.18 & 65.37 & 163.36 \\
\hline 6 & Colombia & $\mathrm{CO}$ & 282.46 & 1.96 & 5805.61 & 36.75 & 5.02 \\
\hline 7 & Hungary & $\mathrm{HU}$ & 125.82 & 2.21 & $12,814.95$ & 17.93 & 6.21 \\
\hline 8 & India & IN & 2263.79 & 7.11 & 1709.59 & 69.21 & 34.99 \\
\hline 9 & Indonesia & IID & 932.26 & 5.02 & 3570.29 & 45.67 & 9.70 \\
\hline 10 & Malaysia & MY & 296.54 & 4.22 & 9508.24 & 121.33 & 33.14 \\
\hline 11 & Mexico & $\mathrm{MC}$ & 1046.92 & 2.29 & 8208.56 & 33.51 & 10.69 \\
\hline 12 & Pakistan & PK & 278.91 & 5.47 & 1443.63 & $37.1^{\wedge}$ & $0.22^{\wedge}$ \\
\hline 13 & Peru & PE & 192.21 & 3.88 & 6049.23 & 42.19 & 1.40 \\
\hline 14 & Philippines & $\mathrm{PH}$ & 304.91 & 6.92 & 2951.07 & 78.63 & 11.76 \\
\hline 15 & Poland & PL & 471.36 & 2.86 & $12,421.32$ & 29.42 & 9.68 \\
\hline 16 & Romania & RO & 187.59 & 4.59 & 9519.88 & $9.40^{*}$ & $0.81^{\wedge}$ \\
\hline 17 & Russian Federation & RU & 1283.16 & -0.22 & 8748.36 & 48.48 & 10.88 \\
\hline 18 & South Africa & $\mathrm{ZA}$ & 295.46 & 0.28 & 5284.60 & 321.98 & 136.21 \\
\hline 19 & Thailand & TH & 407.03 & 3.24 & 5910.62 & 106.37 & 79.85 \\
\hline \multirow[t]{2}{*}{20} & Turkey & TR & 863.71 & 3.18 & $10,862.60$ & 19.89 & 32.63 \\
\hline & World & WRLD & $75,845.11$ & 2.50 & $10,191.31$ & 98.58 & 125.57 \\
\hline
\end{tabular}

Figures as of 2016; ${ }^{\star}$ Figures as of 2012, ^Figures as of 2014, Source: IMF. 
nese and Indian economies are the largest. The exhibit also provides the short-names for all the countries used in this paper.

\section{Methodology}

\subsection{Asymmetric Dynamic Conditional Correlation (ADCC-EGARCH) Model}

Asymmetric dynamic conditional correlation (ADCC) model proposed by Cappiello et al. [39] allows for series specific news impact along with smoothing parameters. It also permits for conditional asymmetries in dynamics of correlation. ADCC specifications are suited to study dynamics of correlation among varied asset classes and also investigate the presence of asymmetric response in the conditional variances as well as correlations to negative returns. We employ the ADCC model to analyze and study the behavior of the sample EMEs including BRICS. Integration across varied sub periods cannot be measured by a static measure of correlation. Therefore, we use Asymmetric DCC-EGARCH (ADCC-EGARCH) model given by Cappiello et al. [39] accounting for heteroscedasticity and also continuously adjusting for time varying volatility. ADCC takes into account the correlations asymmetry which is observed to rise more post-joint negative shock as compared to a positive shock as pointed by Baumohl [49], Exponential GARCH (E-GARCH) model accommodates the asymmetries in conditional variances of asset returns, as the bad news have greater impact than good news [50].

The ADCC-EGARCH as discussed above has been estimated by modifying a program in EViews 9 econometric analysis software as per the requirements of the study to derive and analyze dynamic correlations for our sample countries. Pair wise ADCC is conducted for 20 EMEs. Hence we obtain $190\left({ }^{20} \mathrm{C}_{2}\right)$ such pair-wise correlation series over the entire sample period. Mean ADCC values for each pair are then presented in a matrix. Since this study focuses on BRICS and other EMEs related to BRICS, the average correlation of BRICS has been calculated. The average correlation of each of the EMEs with BRICS has also been calculated to see the associations and interaction of BRICS with each of the EMEs. To capture the dynamics over the pre/during/post crisis period average ADCC values of each of the BRICS with other BRICS members and identified sample economies are also calculated. However, ADCC-EGARCH methodology used for this study as developed by Cappiello et al. [39] is also presented in brief as follows:

The mean equation is specified as an AR (1) process (based on SIC criteria):

$$
r_{i, t}=\alpha_{i}+\sum_{k=1}^{n} \beta_{i, k} r_{i, t-k}+\gamma_{i} r_{U S, t-1}+\varepsilon_{t}
$$

where $r_{t}=r_{i, t}, r_{E M E, t}$ and $\varepsilon_{t}=\left(\varepsilon_{i, t}, \varepsilon_{E M E, t}\right), \varepsilon_{t} \mid 3_{t-1} \sim N\left(0, H_{t}\right)$. Lagged US returns are taken as a proxy for the global effect. $H_{t}$ is the $(n \times n)$ conditional covariance matrix, decomposed as

$$
H_{t}=D_{t} R_{t} D_{t}
$$


$R_{t}$ represents the time-varying correlation matrix, $D_{t}$ represents the $(n \times n)$ diagonal matrix of the time-varying standard deviations for returns, obtained by estimating EGARCH $(1,1)$ process which generates conditional variance of the residuals from mean equation. EGARCH $(1,1)^{4}$ model is given as:

$$
\ln \left(h_{i, t}^{2}\right)=\omega+\psi \ln \left(h_{i, t-1}^{2}\right)+\varphi\left|\frac{\epsilon_{i, t-1}}{h_{i, t-1}}\right|+\delta \frac{\epsilon_{i, t-1}}{h_{i, t-1}}
$$

Estimation results show presence of long run volatility persistence as is indicated by significant value of $\psi$ coefficient. Estimation results are not shown due to scarcity of space. Both ARCH $(\varphi)$ and GARCH $(\delta)$ term measuring size and leverage effect, respectively are also found to be significant for all sample markets. EGARCH model is justified as negative and significant value of $\delta$ coefficient indicates asymmetric effect caused by news on volatility factor which increases more post a negative shock as compared to a positive shock.

Correlation equation as evolved in ADCC model [39] is given by:

$$
Q_{t}=\left(1-\theta_{1}-\theta_{2}\right) \bar{Q}-g \bar{N}+\theta_{1}\left(\varepsilon_{t-1} \varepsilon_{t-1}^{\prime}\right)+\theta_{2} Q_{t-1}+g\left(\eta_{t-1} \eta_{t-1}^{\prime}\right)
$$

where $Q_{t}=\left(q_{i j, t}\right)$ is the $(n \times n)$ symmetric positive definite matrix of $\varepsilon_{0}$ $\bar{Q}=E\left(\varepsilon_{t} \varepsilon_{t}^{\prime}\right)$ is the $(n \times n)$ unconditional correlation-matrix of standardized residuals $\varepsilon_{t}, N=E\left(\eta_{t} \eta_{t}^{\prime}\right)$ and the asymmetric term $g$ captures the periods where both markets jointly experience negative shock. The scalar parameters $\theta_{1}$ and $\theta_{2}$ are non-negative and satisfy $\theta_{1}+\theta_{2}<1$. Finally, dynamic correlation matrix among the two series is represented by:

$$
P_{t}=Q_{t}^{*-1} Q_{t} Q_{t}^{*-1}
$$

where $Q_{t}^{*}=\left[\sqrt{q_{i i t}}\right]$ is diagonal matrix with entries as the square root of $i^{\text {th }}$ diagonal elements of $Q_{t}$

ADCC as a measure of interactions only gives correlations but not spillovers or dominance, however, to study the "to and from" linkages in details, block aggregation technique is used in this study as given under Diebold-Yilmaz framework that was enhanced by Greenwood-Nimmo et al. [3].

\subsection{Diebold and Yilmaz (2012) Spillover Index}

Diebold and Yilmaz [2] have proposed the Spillover index methodology which is based on vector autoregressive (VAR) framework, which allows us to examine spillovers across variables. The contribution of shocks from and to each variable in terms of each variable's forecast error variance through variance decomposition analysis is quantified thereby providing the magnitude and direction of spillovers. Diebold and Yilmaz [2] use generalized VAR frame-work of Pesaran and Shin (1998) and Koop et al. (1996) which yields forecast-error variance decompositions that are invariant to ordering of variables.

Following the spillover index methodology by Diebold and Yilmaz [2]. The authors estimate the results using RATS10.0 econometric analysis software. The pro${ }^{4}$ EGARCH $(1,1)$ is chosen as the preferred model in interest of parsimony of parameters (see Kim and Wang, 2006). 
gram of the said methodology is downloaded from their webpage ${ }^{5}$ which has been modified to analyse the spillovers among the sample markets. Sample series of returns and conditional volatilities derived from EGARCH $(1,1)$ process along with US returns and conditional volatility are provided as input into the software. However, methodology as developed by Diebold and Yilmaz [2] and Greenwood-Nimmo, Nguyen, \& Rafferty [3] used for this study is briefly discussed below.

The $N$ variable VAR of $p^{\text {th }}$ order can be written as: $y_{t}=\sum_{i=1}^{p} \phi_{i} y_{t-i}+\varepsilon_{t}$, where $y_{t}=\left(y_{1 t}, \cdots, y_{N t}\right)$ is a vector with $N$ endogenous variables, $\phi_{i}$ is $N \times N$ parameter matrix and $\varepsilon_{t} \sim(0, \Sigma)$ is vector of innovations. Its moving average representation is written as: $y_{t}=\sum_{i=1}^{\infty} A_{i} \varepsilon_{t-i}$, where $A_{i}=\sum \phi_{j} A_{i-j}$ and $j=1, \cdots, p$.

The H-step ahead forecast error variance decomposition of $I^{\text {th }}$ variable which can be attributed to shocks for $f^{\text {th }}$ variable is:

$$
\theta_{i \leftarrow j}^{g}(H)=\frac{\sigma_{i i}^{-1} \sum_{h=0}^{H-1}\left(e_{i}^{\prime} A_{h} \Sigma e_{j}\right)^{2}}{\sum_{h=0}^{H-1}\left(e_{i}^{\prime} A_{h} \Sigma A_{h}^{\prime} e_{j}\right)}, \text { for } i, j=1, \cdots, N
$$

where $\Sigma$ is the estimated variance matrix for the error term of VAR, $\sigma_{i j}$ is standard deviation for the error term of the $i^{\text {th }}$ equation and $e_{i}$ is the selection vector with one for the $i^{\text {th }}$ element and zero otherwise. Each forecast error variance decomposition is normalized given by the row sum as:

$$
\tilde{\theta}_{i \leftarrow j}^{g}(H)=\frac{\theta_{i \leftarrow j}^{g}(H)}{\sum_{j=1}^{N} \theta_{i \leftarrow j}^{g}(H)}
$$

$N \times N$ Connectedness matrix can thus be constructed using the forecast error variance decompositions as follows:

$$
C(H)=\left[\begin{array}{cccc}
\tilde{\theta}_{1 \leftarrow 1}^{g}(H) & \theta_{1 \leftarrow 2}^{g}(H) & \cdots & \theta_{1 \leftarrow N}^{g}(H) \\
\theta_{\leftarrow \leftarrow 1}^{g}(H) & \theta_{2 \leftarrow 2}^{g}(H) & \cdots & \theta_{2 \leftarrow N}^{g}(H) \\
\vdots & \vdots & \ddots & \vdots \\
\theta_{N \leftarrow 1}^{g}(H) & \theta_{N \leftarrow 2}^{g}(H) & \cdots & \theta_{N \leftarrow N}^{g}(H)
\end{array}\right]
$$

where $\tilde{\theta}_{i \leftarrow j}^{g}(H)$ measures the pairwise spillover from variable $j$ to variable $i$.

\subsection{Greenwood-Nimmo [3] Block Aggregation Framework}

While Diebold-Yilmaz framework provides the measure of pair wise directional spillovers among individual markets, it does not quantify the spillovers between a group of variables, Greenwood-Nimmo et al. [3] extend Diebold-Yilmaz framework by exploiting block aggregation of the connectedness matrix which applies an aggregation routine for grouping sets of individual variables.

We, therefore, adopt the same methodology to examine linkages amongst the EME including BRICS. We examine the linkages among 20 EMEs and US market representing the global market system, wherein each market encompasses two variables-return and conditional volatility in a similar manner as in Greenwood-Nimmo, Nguyen and Shin [3] but with only returns and conditional volatilities. The variables are arranged in the order $y_{t}=\left(r_{1 t}, v_{1 t}, r_{2 t}, v_{2 t}, \cdots, r_{N t}, v_{N t}\right)$. ${ }^{5}$ https://estima.com/ratshelp/index.html?dieboldyilmazspilloverpapers.html. 
Generalized VAR framework adopted in Diebold and Yilmaz [2] ensures that forecast-error decomposition is not sensitive to the variable re-ordering and hence supports any desired block structure. Therefore, the connectedness matrix is arranged in the following form:

$$
C(H)=\left[\begin{array}{cccc}
B_{1 \leftarrow 1}^{g}(H) & B_{1 \leftarrow 2}^{g}(H) & \cdots & B_{1 \leftarrow N}^{g}(H) \\
B_{2 \leftarrow 1}^{g}(H) & B_{2 \leftarrow 2}^{g}(H) & \cdots & B_{2 \leftarrow N}^{g}(H) \\
\vdots & \vdots & \ddots & \vdots \\
B_{N \leftarrow 1}^{g}(H) & B_{N \leftarrow 2}^{g}(H) & \cdots & B_{N \leftarrow N}^{g}(H)
\end{array}\right],
$$

where, $B_{i \leftarrow j}^{g}(H)=\left[\begin{array}{ccc}\theta_{r_{i} \leftarrow r_{j}}^{g}(H) & \theta_{r_{i} \leftarrow v_{j}}^{g}(H) & \theta_{r_{i} \leftarrow s_{j}}^{g}(H) \\ \theta_{v_{i} \leftarrow r_{j}}^{g}(H) & \theta_{v \leftarrow v_{j}}^{g}(H) & \theta_{v_{i} \leftarrow s_{j}}^{g}(H) \\ \theta_{s_{i} \leftarrow r_{j}}^{g}(H) & \theta_{s_{i} \leftarrow v_{j}}^{g}(H) & \theta_{s_{i} \leftarrow s_{j}}^{g}(H)\end{array}\right]$, for $i, j=1,2, \cdots, N$

Total within market forecast error variance contribution for market $i$ is given as:

$$
W_{i \leftarrow i}^{g}(H)=\frac{1}{m} \cdot e_{m}^{\prime} \cdot B_{i \leftarrow i}^{g}(H) \cdot e_{m},
$$

and the total pairwise directional spillover from market $j$ to market $i(i \neq j)$ at horizon $H$ is given as:

$$
P_{i \leftarrow j}^{g}(H)=\frac{1}{m} \cdot e_{m}^{\prime} \cdot B_{i \leftarrow j}^{g}(H) \cdot e_{m}
$$

where $m$ is the number of variables that each group is composed of (in this case, $m=2$ ) and $e_{m}$ is $m \times 1$ vector of ones.

Hence, the aggregated connectedness matrix following Greenwood-Nimmo et al. [3] can be written as:

$$
C(H)=\left[\begin{array}{cccc}
W_{1 \leftarrow 1}^{g}(H) & P_{1 \leftarrow 2}^{g}(H) & \cdots & P_{1 \leftarrow N}^{g}(H) \\
P_{2 \leftarrow 1}^{g}(H) & W_{2 \leftarrow 2}^{g}(H) & \cdots & P_{2 \leftarrow N}^{g}(H) \\
\vdots & \vdots & \ddots & \vdots \\
P_{N \leftarrow 1}^{g}(H) & P_{N \leftarrow 2}^{g}(H) & \cdots & W_{N \leftarrow N}^{g}(H)
\end{array}\right]
$$

Now, total within-market contribution, $W_{i \leftarrow i}^{g}(H)$, is decomposed into common-variable forecast error variance contribution within-market $i, O_{i \leftarrow i}^{g}(H)$, and cross-variable effects, $C_{i \leftarrow i}^{g}(H)$, which are given as follows:

$$
O_{i \leftarrow i}^{g}(H)=\frac{1}{m} \operatorname{trace}\left(B_{i \leftarrow i}^{g}(H)\right) \text { and } C_{i \leftarrow i}^{g}(H)=W_{i \leftarrow i}^{g}(H)-O_{i \leftarrow i}^{g}(H)
$$

$O_{i \leftarrow i}^{g}(H)$ is proportion of forecast error variance of $y_{i, t}$ not attributable to spillovers among moments within market $i$ nor to the spillovers from other markets to market $i$. On the other hand, $C_{i \leftarrow i}^{g}(H)$ is proportion of forecast error variance of $y_{i, t}$ that is ascribed to spillovers among moments within-market $i$.

We can also decompose total pair-wise directional spillovers into common-variable, $O_{i \leftarrow j}^{g}(H)$, and cross-variable effects, $C_{i \leftarrow j}^{g}(H)$, expressed as: 


$$
O_{i \leftarrow j}^{g}(H)=\frac{1}{m} \operatorname{trace}\left(B_{i \leftarrow j}^{g}(H)\right) \text { and } C_{i \leftarrow j}^{g}(H)=W_{i \leftarrow j}^{g}(H)-O_{i \leftarrow j}^{g}(H) \text {, }
$$

where $i \neq j$.

Here, $O_{i \leftarrow j}^{g}(H)$ measures proportion of common-variable forecast error variance of $y_{i, t}$ that is attributable to spillovers from other markets to the market $i$, while $C_{i \leftarrow j}^{g}(H)$ captures the proportion of forecast error variance of $y_{i, t}$ that is ascribed to spillovers among moments from other markets to the market i.

Total directional spillover of market $i$ to/from all other markets in the model can also be estimated from the connectedness matrix. Total directional spillovers transmitted by market $i$ from and to all other markets, in other words, the aggregate from and to connectedness of market $i$ are expressed as:

$$
F_{i \leftarrow \cdot}^{g}(H)=\sum_{j=1}^{N} P_{i \leftarrow j}^{g}(H) \text { and } T_{i \leftarrow \cdot}^{g}(H)=\sum_{j=1}^{N} P_{j \leftarrow i}^{g}(H) \text {, respectively. }
$$

Gross and Net directional spillover of market $i$ can be obtained as follows:

$G_{i}^{g}(H)=T_{i \leftarrow \bullet}^{g}(H)+F_{i \leftarrow \bullet}^{g}(H)$ and $N_{i}^{g}(H)=T_{i \leftarrow \bullet}^{g}(H)-F_{i \leftarrow \bullet}^{g}(H)$, respectively.

Similarly, total directional spillover of market $i$ to/from BRICS markets along with Gross and Net directional Spillovers of market $i$ (in terms of BRICS) in the model is also estimated from the connectedness matrix.

ADCC as a measure of interactions only gives conditional correlations but not spillovers or dominance, thereby not showing flow of information from where and to where. Therefore, to study the "to and from" linkages over the first two moments in detail, we utilize the Diebold-Yilmaz framework. While Diebold-Yilmaz framework provides the measure of pair wise directional spillovers among individual markets, it does not quantify the spillovers between a group of variables, Greenwood-Nimmo framework extend Diebold-Yilmaz framework by exploiting block aggregation of the connectedness matrix which applies an aggregation routine for grouping sets of individual variables and thereby presenting a holistic view over the two moments also providing information regarding openness and dominance of a country by Gross and Net Spillovers respectively.

\section{Empirical Results}

\subsection{Descriptives}

The descriptive statistics for the sample countries are shown in Table 2. The highest daily mean return is for Colombia $(0.0815 \%)$ and lowest for Poland $(0.008 \%)$. The daily standard deviation as a measure of volatility is highest for Turkey (1.95\%) and lowest for Columbia (0.976\%) followed by Chile $(0.987 \%)$. All return series exhibit negative skewness and high kurtosis (leptokurtic) implying that they are fat-tailed distributions. There is violation of normality assumption as shown by Jarque-Berra (JB) statistics. All sample series are serially correlated as indicated by Ljung-Box Q-Statistic. ARCH LM test also shows strong evidence of conditional hetroscedasticity implying volatility clustering in 
Table 2. Descriptive statistics for sample equity markets.

\begin{tabular}{|c|c|c|c|c|c|c|c|c|c|c|c|}
\hline Country & Mean & $\begin{array}{l}\text { Standard } \\
\text { Deviation }\end{array}$ & Skewness & Kurtosis & Jarque-Bera & P-val & $\begin{array}{c}\text { ARCH LM } \\
\text { Obs*R-squared }\end{array}$ & P Ch Sq. & $\mathrm{LB}(12)$ & Prob. & Obsv. \\
\hline AR & 0.00024 & 0.01720 & -0.66 & 11.57 & $13,500.36^{*}$ & 0.00 & $787.9174^{*}$ & 0.00 & $1133.3^{*}$ & 0.00 & 4305 \\
\hline $\mathrm{BR}$ & 0.00019 & 0.01626 & -0.35 & 7.65 & $3967.62^{*}$ & 0.00 & $862.4861^{\star}$ & 0.00 & $1191.4^{*}$ & 0.00 & 4305 \\
\hline $\mathrm{CL}$ & 0.00023 & 0.00987 & -0.30 & 11.01 & $11,581.54^{*}$ & 0.00 & $609.8632^{*}$ & 0.00 & $1350.9^{*}$ & 0.00 & 4305 \\
\hline $\mathrm{CN}$ & 0.00027 & 0.01244 & -0.27 & 8.21 & $4920.29^{*}$ & 0.00 & $673.2203^{*}$ & 0.00 & $1148.6^{*}$ & 0.00 & 4305 \\
\hline $\mathrm{CO}$ & 0.00082 & 0.00976 & -0.09 & 17.03 & $35,301.07^{*}$ & 0.00 & $633.1519^{*}$ & 0.00 & $1464.8^{*}$ & 0.00 & 4305 \\
\hline HU & 0.00025 & 0.01567 & -0.29 & 13.09 & $18,325.47^{*}$ & 0.00 & $606.3382^{*}$ & 0.00 & $1150.6^{*}$ & 0.00 & 4305 \\
\hline IID & 0.00056 & 0.01414 & -0.56 & 9.11 & $6917.06^{*}$ & 0.00 & $1095.507^{*}$ & 0.00 & $1328.3^{*}$ & 0.00 & 4305 \\
\hline IN & 0.00036 & 0.01198 & -0.36 & 10.50 & $10,182.90^{*}$ & 0.00 & $775.5286^{*}$ & 0.00 & $1276.6^{*}$ & 0.00 & 4305 \\
\hline MC & 0.00032 & 0.01187 & -0.46 & 8.86 & $6306.40^{*}$ & 0.00 & $1328.804^{*}$ & 0.00 & $1293.2^{*}$ & 0.00 & 4305 \\
\hline MY & 0.00019 & 0.00737 & -0.39 & 7.30 & $3431.07^{*}$ & 0.00 & $1082.982^{*}$ & 0.00 & $1424^{*}$ & 0.00 & 4305 \\
\hline PE & 0.00056 & 0.01307 & -0.33 & 8.07 & $4683.22^{*}$ & 0.00 & $892.793^{*}$ & 0.00 & $1121.6^{*}$ & 0.00 & 4305 \\
\hline $\mathrm{PH}$ & 0.00031 & 0.01112 & 0.21 & 12.10 & $14,901 \cdot 10^{*}$ & 0.00 & $746.5212^{\star}$ & 0.00 & $1358.5^{\star}$ & 0.00 & 4305 \\
\hline PK & 0.00027 & 0.01164 & -0.56 & 8.28 & $5224.70^{*}$ & 0.00 & $1128.52^{*}$ & 0.00 & $1523.1^{*}$ & 0.00 & 4305 \\
\hline PL & 0.00008 & 0.01406 & -0.30 & 7.60 & $3865.33^{*}$ & 0.00 & $793.8741^{\star}$ & 0.00 & $1175.3^{*}$ & 0.00 & 4305 \\
\hline RO & 0.00062 & 0.01104 & -0.51 & 10.68 & $10,777.68^{*}$ & 0.00 & $745.2243^{*}$ & 0.00 & $1342.8^{*}$ & 0.00 & 4305 \\
\hline RU & 0.00028 & 0.01703 & -0.38 & 14.72 & $24,752.76^{*}$ & 0.00 & $1144.518^{*}$ & 0.00 & $1232.4^{*}$ & 0.00 & 4305 \\
\hline $\mathrm{TH}$ & 0.00044 & 0.01149 & -0.46 & 9.05 & $6712.28^{*}$ & 0.00 & $508.9526^{*}$ & 0.00 & $1289.7^{*}$ & 0.00 & 4305 \\
\hline TR & 0.00012 & 0.01949 & -0.78 & 14.12 & $22,618.51^{*}$ & 0.00 & $1054.976^{*}$ & 0.00 & $1240^{*}$ & 0.00 & 4305 \\
\hline $\mathrm{ZA}$ & 0.00026 & 0.01306 & -0.36 & 8.08 & $4727.57^{\star}$ & 0.00 & $624.01^{*}$ & 0.00 & $1144.3^{*}$ & 0.00 & 4305 \\
\hline
\end{tabular}

Notes: i) JB denotes Jarque-Bera test and has null hypothesis of normal distribution; ii) LB denotes Ljung-Box Q-statistic that is reported at $12^{\text {th }}$ lag; (iii) ARCH LM denotes ARCH Lagrange Multiplier test of conditional heteroscedasticity; iv) Obsv. denotes number of observations in the return series; v) “»” indicates significance at 0.05 level.

sample series and the need for greater analysis of second moment. Augmented Dickey-Fuller Dickey \& Fuller (1979) and Phillips \& Perron (1998) tests have also been performed as a pre-cursor to time-series analysis. The results presented in Table 3 reveal that all sample return series are integrated at level.

\subsection{ADCC Model Results}

\subsubsection{ADCC Full Sample Mean Correlation Results}

The dynamic conditional correlation (ADCC Model) is estimated using two-day moving average of log-returns to measure the co-movements between the markets. Sehgal, Gupta, \& Deisting [42] find that correlation coefficients for the advanced economies of the European Economic and Monetary Union (Belgium, France, Germany, Italy, Netherlands and Spain) remained over 0.84 during all the sub-periods of their study. In contrast, we find that the correlations between EMEs including BRICS are moderate.

Table 4 (Panel: A) provides the average correlation coefficients for all of the 20 EMEs. The average correlations have been estimated by taking the mean of 
Table 3. Test of stationarity of sample equity return series.

\begin{tabular}{|c|c|c|}
\hline Country & ADF (level) & PP (level) \\
\hline AR & $-15.30557^{\star}$ & $-35.27552^{\star}$ \\
\hline BR & $-13.28381^{*}$ & $-34.22627^{\star}$ \\
\hline CL & $-15.68548^{*}$ & $-31.72835^{\star}$ \\
\hline $\mathrm{CN}$ & $-10.91453^{*}$ & $-34.95765^{\star}$ \\
\hline $\mathrm{CO}$ & $-10.94014^{*}$ & $-31.53168^{\star}$ \\
\hline $\mathrm{HU}$ & $-11.88432^{*}$ & $-35.04733^{\star}$ \\
\hline IID & $-10.31783^{*}$ & $-32.76139^{\star}$ \\
\hline IN & $-13.88894^{*}$ & $-38.31854^{\star}$ \\
\hline MC & $-10.71925^{\star}$ & $-32.26346^{*}$ \\
\hline MY & $-11.61185^{\star}$ & $-32.01808^{\star}$ \\
\hline $\mathrm{PE}$ & $-12.18449^{*}$ & $-34.37877^{\star}$ \\
\hline $\mathrm{PH}$ & $-12.99415^{\star}$ & $-31.5261^{\star}$ \\
\hline PK & $-12.73938^{*}$ & $-32.6695^{\star}$ \\
\hline PL & $-14.89284^{*}$ & $-34.02521^{\star}$ \\
\hline RO & $-11.95578^{*}$ & $-33.33596^{\star}$ \\
\hline RU & $-9.553872^{*}$ & $-33.22577^{\star}$ \\
\hline $\mathrm{TH}$ & $-12.40105^{\star}$ & $-33.10839^{\star}$ \\
\hline TR & $-12.76214^{*}$ & $-34.03151^{\star}$ \\
\hline $\mathrm{ZA}$ & $-15.04511^{*}$ & $-33.90245^{*}$ \\
\hline
\end{tabular}

Notes: i) The value reported is t-stat value of ADF and PP unit root tests; ii) * denotes level of significance at $5 \%$ whose critical values at $95 \%$ confidence level is -3.41 .

Table 4. ADCC results of sample equity markets.

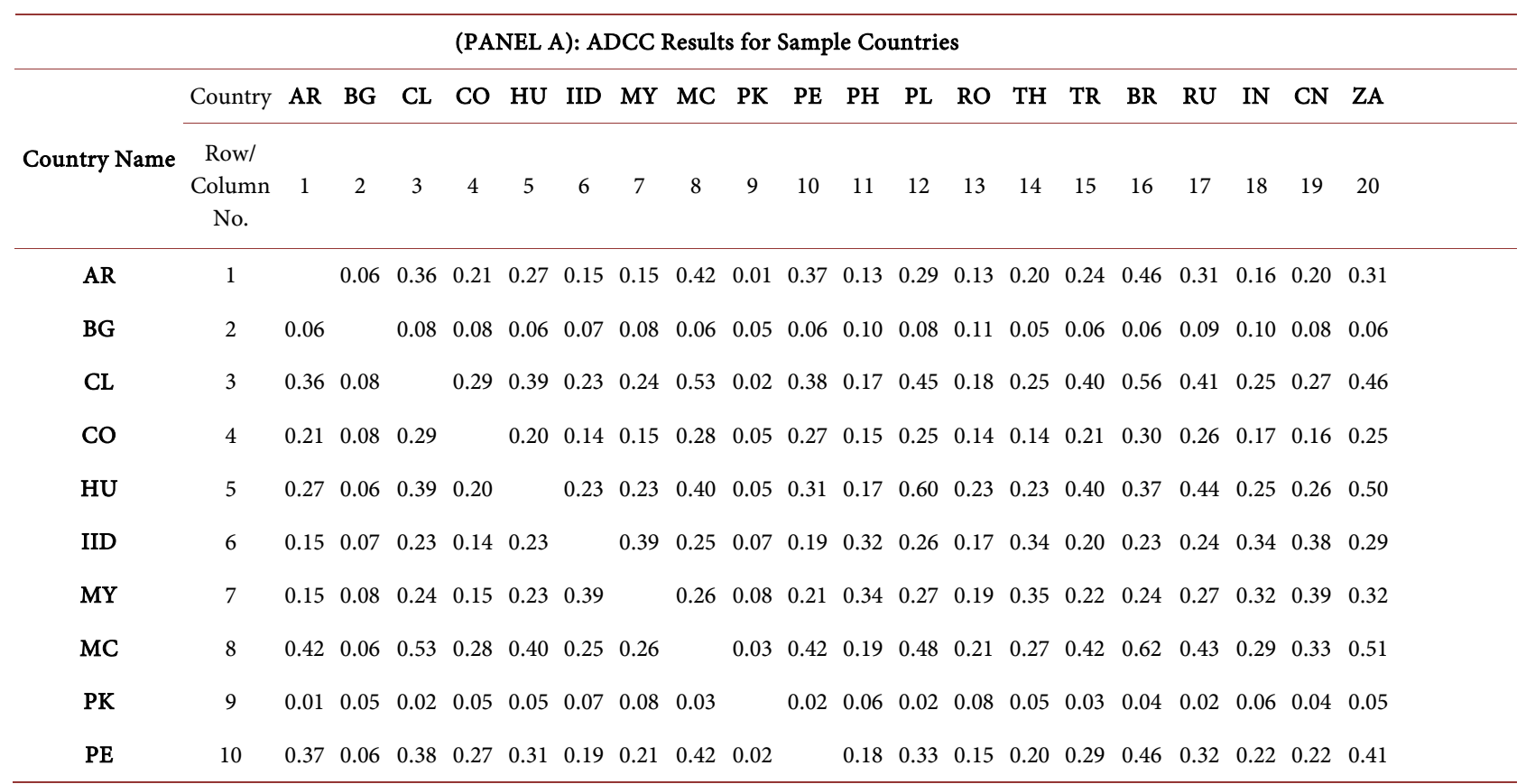


Continued

\begin{tabular}{|c|c|c|c|c|c|c|c|c|c|c|c|c|c|c|c|c|c|c|c|c|c|}
\hline $\mathrm{PH}$ & 11 & 0.13 & 0.10 & 0.17 & 0.15 & 0.17 & 0.32 & 0.34 & 0.19 & 0.06 & 0.18 & & 0.19 & 0.18 & 0.26 & 0.18 & 0.18 & 0.18 & 0.25 & 0.28 & 0.22 \\
\hline PL & 12 & 0.29 & 0.08 & 0.45 & 0.25 & 0.60 & 0.26 & 0.27 & 0.48 & 0.02 & 0.33 & 0.19 & & 0.28 & 0.28 & 0.44 & 0.43 & 0.51 & 0.32 & 0.32 & 0.55 \\
\hline $\mathrm{TH}$ & 14 & 0.20 & 0.05 & 0.25 & 0.14 & 0.23 & 0.34 & 0.35 & 0.27 & 0.05 & 0.20 & 0.26 & 0.28 & 0.16 & & 0.23 & 0.24 & 0.26 & 0.32 & 0.37 & 0.30 \\
\hline TR & 15 & 0.24 & 0.06 & 0.40 & 0.21 & 0.40 & 0.20 & 0.22 & 0.42 & 0.03 & 0.29 & 0.18 & 0.44 & 0.20 & 0.23 & & 0.41 & 0.39 & 0.26 & 0.27 & 0.46 \\
\hline BR & 16 & 0.46 & 0.06 & 0.56 & 0.30 & 0.37 & 0.23 & 0.24 & 0.62 & 0.04 & 0.46 & 0.18 & 0.43 & 0.17 & 0.24 & 0.41 & & 0.43 & 0.27 & 0.30 & 0.47 \\
\hline RU & 17 & 0.31 & 0.09 & 0.41 & 0.26 & 0.44 & 0.24 & 0.27 & 0.43 & 0.02 & 0.32 & 0.18 & 0.51 & 0.21 & 0.26 & 0.39 & 0.43 & & 0.28 & 0.32 & 0.49 \\
\hline IN & 18 & 0.16 & 0.10 & 0.25 & 0.17 & 0.25 & 0.34 & 0.32 & 0.29 & 0.06 & 0.22 & 0.25 & 0.32 & 0.21 & 0.32 & 0.26 & 0.27 & 0.28 & & 0.40 & 0.33 \\
\hline $\mathrm{CN}$ & 19 & 0.20 & 0.08 & 0.27 & 0.16 & 0.26 & 0.38 & 0.39 & 0.33 & 0.04 & 0.22 & 0.28 & 0.32 & 0.21 & 0.37 & 0.27 & 0.30 & 0.32 & 0.40 & & 0.36 \\
\hline
\end{tabular}

(Panel B): Average ADCC Results and Their Comparisons

\begin{tabular}{|c|c|c|c|c|c|c|c|c|c|c|c|c|c|c|c|c|c|c|c|c|c|c|}
\hline $\begin{array}{l}\text { Average ADCC } \\
\text { Between } \\
\text { Country "i" and } \\
\text { all other EMEs }\end{array}$ & 21 & 0.23 & 0.07 & 0.31 & 0.19 & 0.29 & 0.24 & 0.25 & 0.34 & 0.04 & 0.26 & 0.20 & 0.33 & 0.18 & 0.24 & 0.28 & 0.33 & 0.31 & 0.25 & 0.27 & 0.35 & $\begin{array}{c}\text { BRICS } \\
\text { AVERAGE }\end{array}$ \\
\hline $\begin{array}{l}\text { Average ADCC } \\
\text { Between } \\
\text { Country " } i " \text { and } \\
\text { BRICS }\end{array}$ & 22 & 0.29 & 0.08 & 0.39 & 0.23 & 0.36 & 0.30 & 0.31 & 0.44 & 0.04 & 0.33 & 0.22 & 0.43 & 0.21 & 0.30 & 0.36 & 0.37 & 0.38 & 0.32 & 0.35 & 0.41 & 0.37 \\
\hline $\begin{array}{l}\text { Classification of } \\
\text { Sample EMEs* }\end{array}$ & 23 & low & low & high & low & low & low & low & high & low & low & low & high & low & low & low & high & high & low & low & high & \\
\hline
\end{tabular}

Notes: i) In Panel A the mean ADCC values between sample countries are reported. These figures have been estimated taking the mean of time-varying ADCC values; ii) In Panel B the Average of ADCC values for a sample country " $i$ " with other EME. The Average of ADCC for a country "i" with BRICS is also provided. This value is then compared with the average of ADCC values among BRICS counties. ${ }^{*}$ Countries that have ADCC values higher than BRICS are reported as "high" else "low".

time-varying ADCC values. The highest average correlation is exhibited by Mexico-Brazil (0.624). For Mexico, Brazil is the most important export market in Latin America, and the most important destination of foreign investment in the region. Further, the presence of Brazil and Mexico is essential for regional integration initiatives in Latin American region. Table 4 (Panel: B) shows (i) The average correlation of each EMEs with all other EMEs (Row 21), (ii) Average correlation of each EMEs with BRICS (Row 22) and (iii) Classification of each EMEs into High (Low) if average correlation of that EME with BRICS is greater (less) than Average correlation amongst BRICS (Row 23). BRICS among themselves show an average correlation of 0.366 , Within BRICS, South Africa exhibits the highest correlation with BRIC as 0.412 and India has the lowest as 0.321 with other BRICS members. Among the other EMEs, Chile (0.388), Mexico (0.436) Poland (0.426) exhibit higher correlation with BRICS than the BRICS average. Hungary (0.364) and Turkey (0.358) have correlations close to the BRICS average. Within these EMEs, Mexico has the highest association with BRICS followed by Poland. Acronym like BRIC $+M$ has been used extensively to define the similarity in terms of economy and other parameters. Mexico has taken part in the ninth BRICS summit held in China in 2017 and is also open to 
increased cooperation with the BRICS as it seeks to diversify its trade alliances and export markets. China has already established strategic partnership with Mexico and signed FTA's with Chile. Another popular acronym is BRIC + T (Turkey). China and Russia are important trading partners with Turkey. Turkey also has foreign trade dependence for inputs that leads to a strong trade relation with BRICS. Turkey has also been growing its interest in BRICS and talks have been in air since 2010, with a few studies evaluating the feasibility of Turkey and Mexico joining BRICS. (Dahlhaus, Guénette, \& Vasishtha, 2017; Ersungur, Boz, \& Çınar, 2017; BRICS Think Tanks Council, 2015; Dahlhaus, 2015; Bacik, 2013).

Dua \& Tuteja [45] identify the Global Financial Crisis from 2008-2009. Following their work, we study our sample in three periods: 1) Pre-crisis period from 2001-2007, 2) Crisis period 2008-2009 and 3) Post-crisis period from 2010 onwards.

\subsubsection{Time Varying ADCC Results}

Figure 1 shows 11 graphs. Graphs (a) to (e) show the average ADCC values of each of BRICS with other BRICS markets over the sample period. Graph (f) shows the average BRICS ADCC values. Graph (g) to (k) show average ADCC values over the sample period of each EME with BRICS (reported only for those EMEs that have average ADCC values higher than BRICS namely Chile, Hungary, Mexico, Poland and Turkey. The crisis period has also been highlighted,
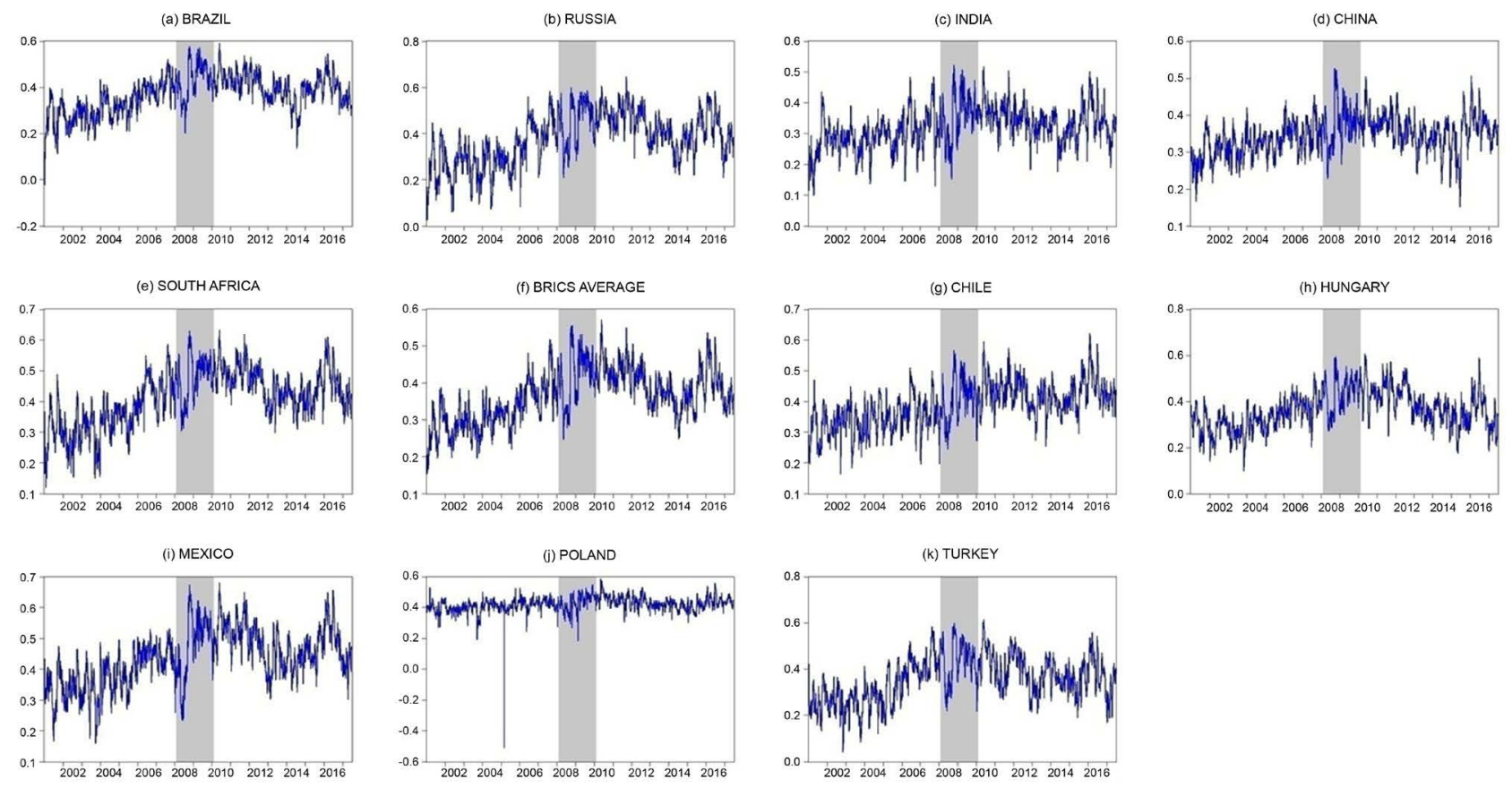

Figure 1. Time varying ADCC graphs of select emerging equity markets with BRICS. Notes: i) The graphs in the figure show time varying conditional correlations of only for those EMEs that have average ADCC values higher than BRICS with rest of the BRICS markets, computed from the ADCC model; ii) Graphs from (a) to (e) show average ADCC values of each of BRICS with other BRICS markets over the sample period. Graph (f) shows the average BRICS ADCC values, Graph (g) to (k) represent Chile, Hungary, Mexico, Poland and Turkey; iii) The crisis period has also been highlighted, reflected by the shaded region in each graph; iv) $\mathrm{x}$-axis represents: Year, $\mathrm{y}$-axis represents: Average ADCC values. 
reflected by the shaded area. Average correlation for BRICS is 0.318 during the pre-crisis period which increased to 0.418 in the crisis period, and marginally declines to 0.396 during the post-crisis period. The graphs in Figure 1 show that the average correlations have increased in the crisis period. The general increase in ADCC values from normal to crisis period may not imply higher (showing) integration, but rather depict contagion effects in BRICS and other EMEs. The correlation of Mexico with BRICS has increased sharply from 0.377 in the pre-crisis period to 0.479 in the post-crisis period. There have been various studies (Blagrave \& Vesperoni, 2018; Cashin, Mohaddes, \& Raissi, 2017) that highlight China's meltdown in early 2015 with lower growth targets, falling commodity prices and depreciating Chinese Yuan against US dollar. The same is reflected by steep rise in correlations of China with BRICS, and overall rise in BRICS average correlations showing contagion effect among the group because of their association with China.

ADCC is a measure of association only. It does not show interactions and hence, analysis cannot be made on information spillovers or dominance. The results from the study of "to and from" linkages in details using the Block aggregation technique under Diebold-Yilmaz framework as enhanced by Greenwood-Nimmo et al. [3] is presented in the next sub-section.

\subsection{Diebold and Yilmaz [2] Spillover Index Results}

We employ full sample Diebold and Yilmaz [2] spillover index methodology The analysis is done by estimating the connectedness matrix under Diebold-Yilmaz framework wherein optimal lag length is determined by minimizing Schwarz Information Criterion (SIC) and forecast horizon is set to $\mathrm{H}=10$ days.

\subsubsection{Return and Volatility Spillovers}

Spillover index methodology as proposed by Diebold and Yilmaz [2] is employed to return and conditional volatility of 20 sample markets along with US as a global factor that gives a $42 \times 42$ connectedness matrix. The matrix quantifies magnitude of pairwise linkages between the first two moments of each market in the sample. The connectedness matrix depicting pairwise spillovers across return and volatility for all 21 markets is presented in Table 5. It presents magnitude of pairwise linkages between individual variables for the full sample period. The diagonal elements in the matrix represent within moment spillovers and off-diagonal elements represent cross-moment/directional spillovers.

Considering the return spillover across the BRICS markets, within own-market spillover ranges around 23\%. The cross return spillovers amongst BRICS lie between $2 \%$ to $8 \%$ which implies that the given percentage of the return spillovers in each market is being explained by each of the other BRICS countries. Considering other EMEs with BRICS, the return spillovers range from $0.1 \%$ to $11.1 \%$. Brazil-South Africa, Brazil-Chile, South Africa-Russia, South Africa-Hungary, Brazil-Mexico, South Africa-Mexico, Brazil-Peru, South Africa-Peru, Russia-Poland and South Africa-Poland have higher than average return spillover (about 6\%). 
Table 5. Return \& volatility spillovers for all sample equity markets.

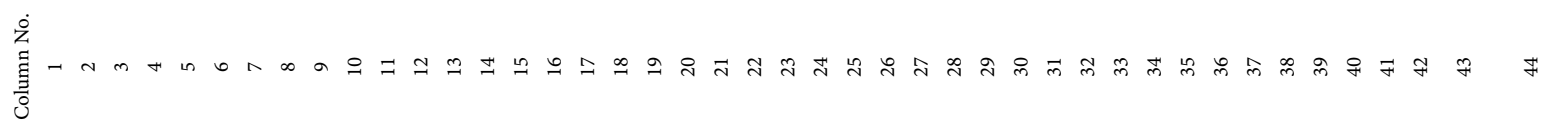

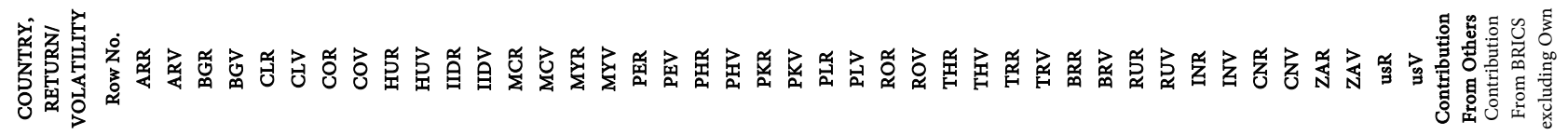

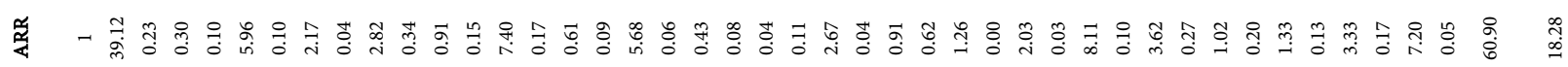

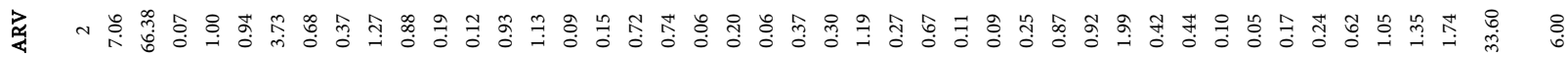

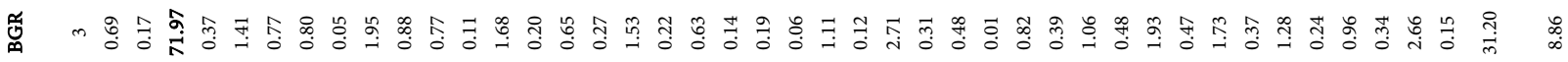

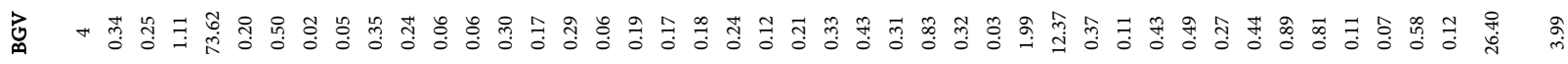

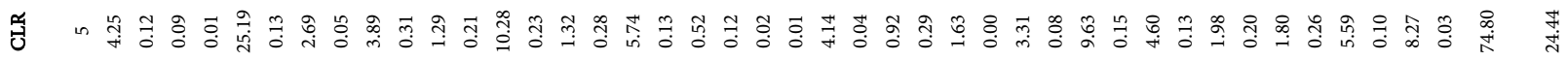

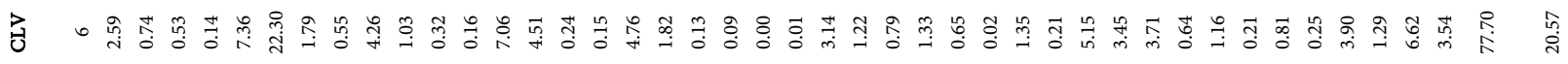

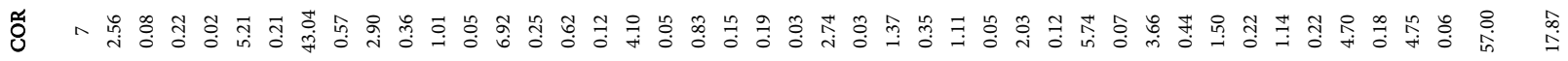

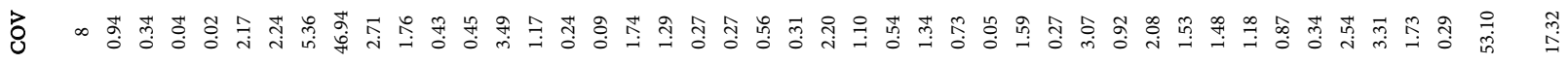
屈

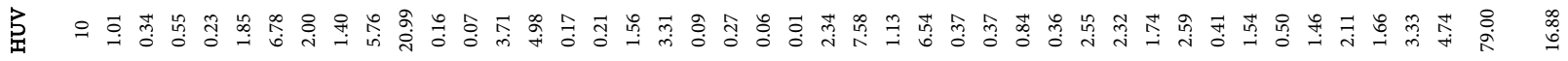

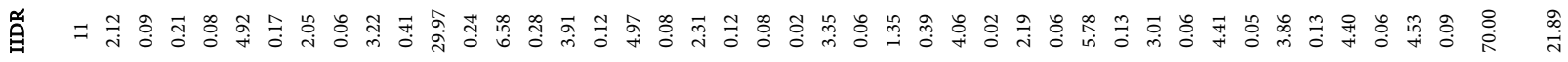

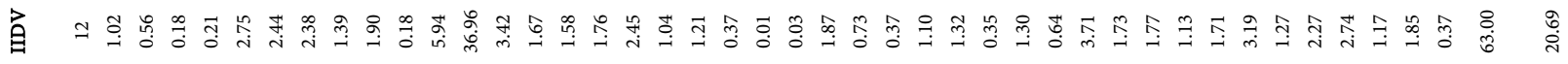

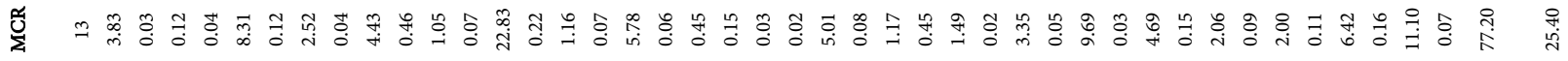

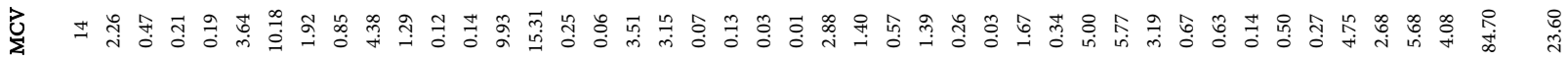

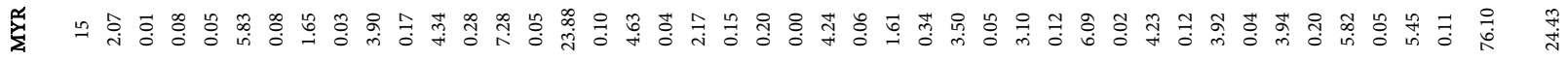

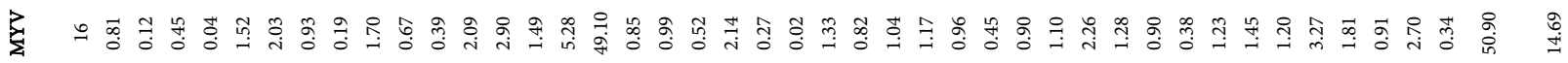

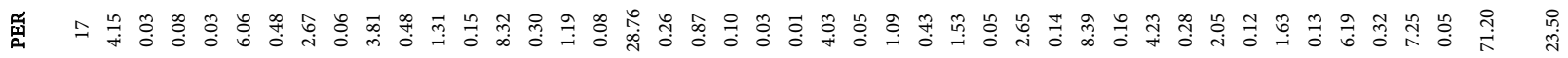

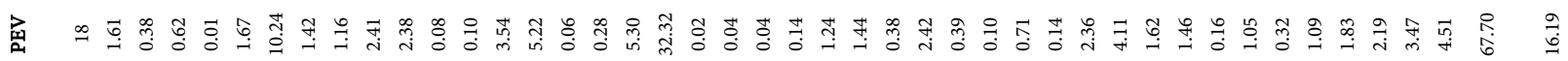

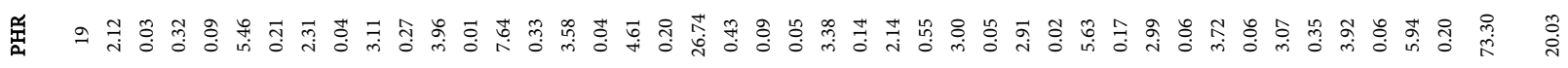




\section{Continued}

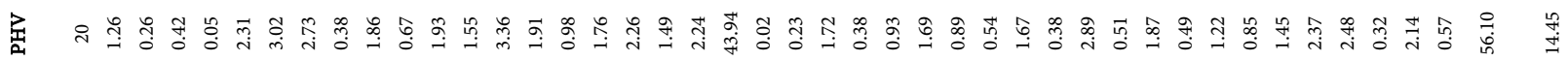

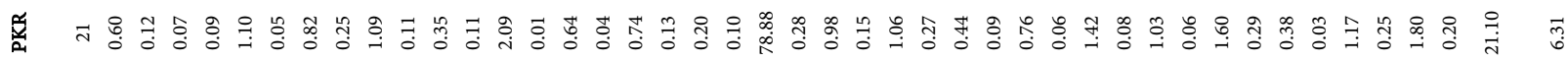

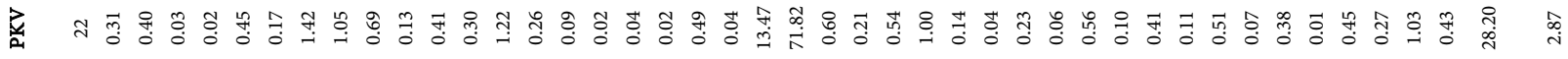

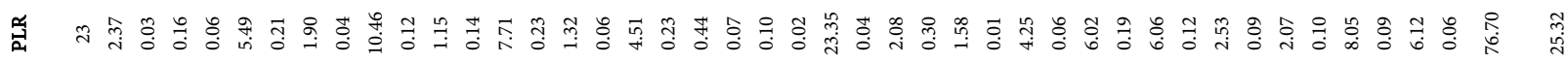

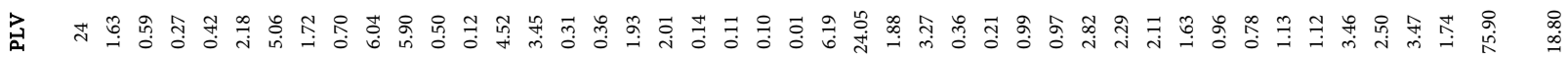

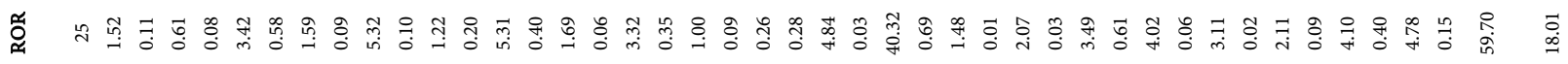

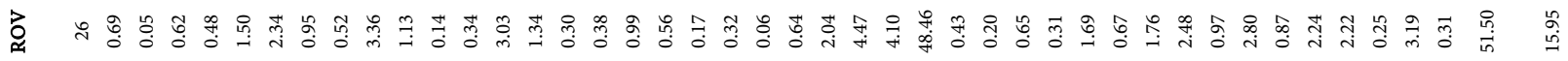

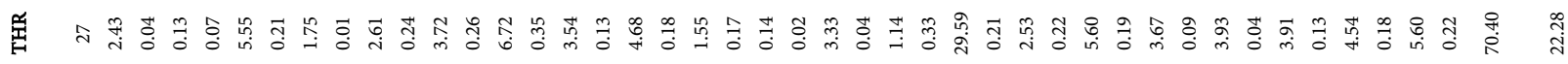

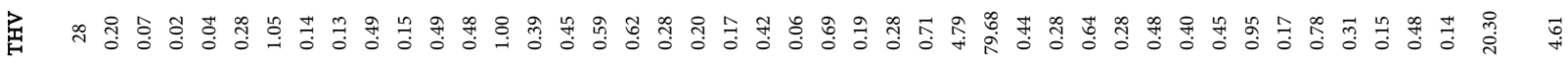

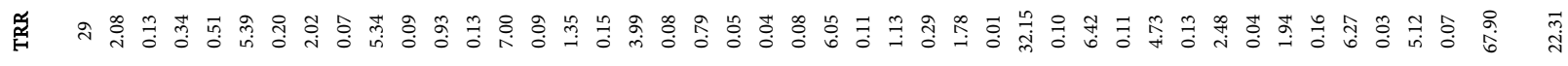

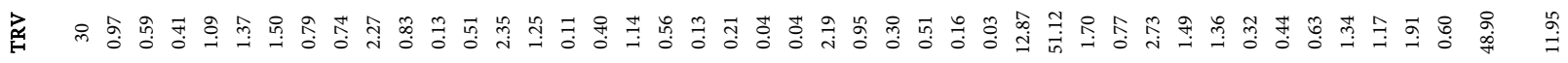

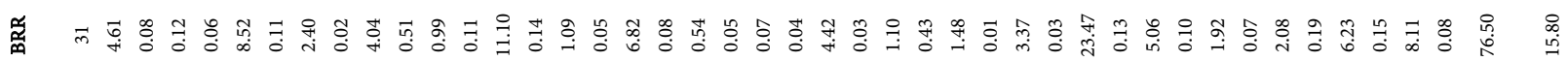

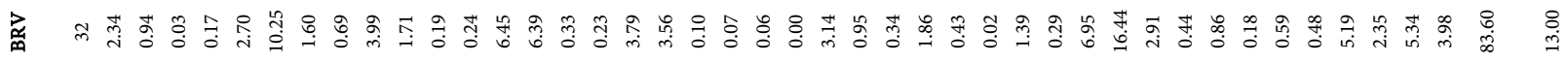

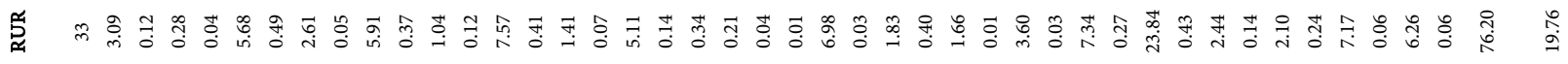

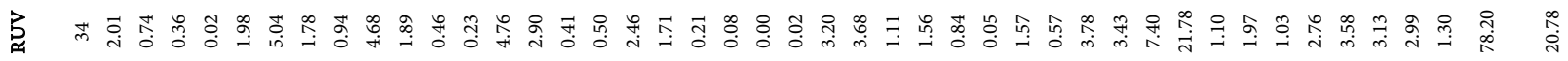

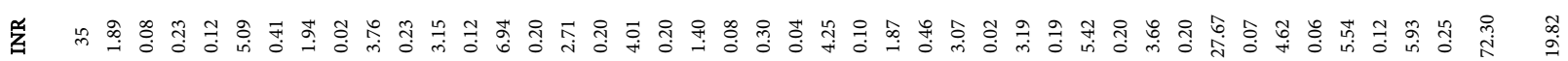

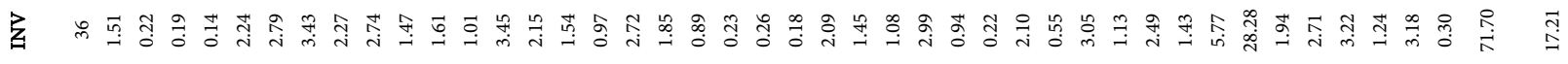

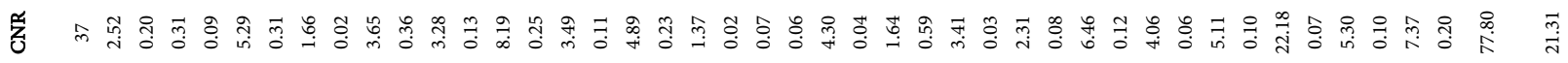

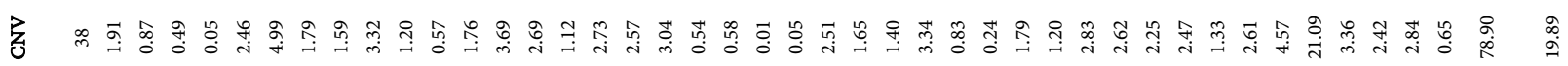

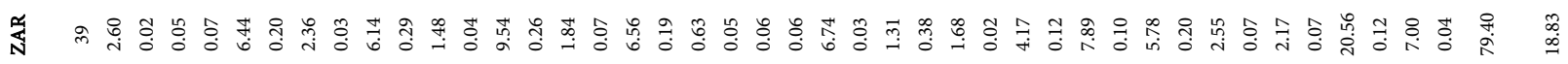

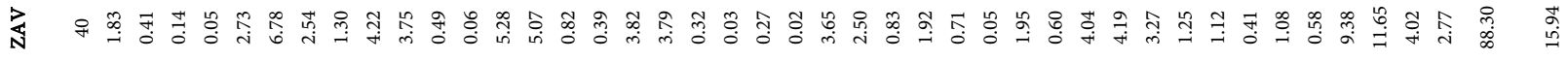

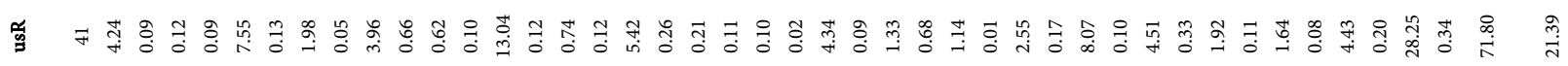

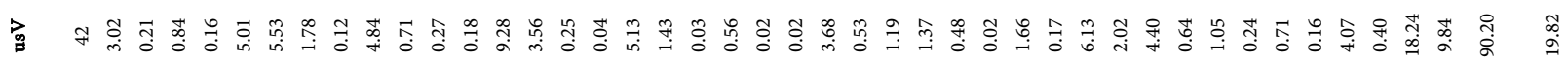




\section{Continued}

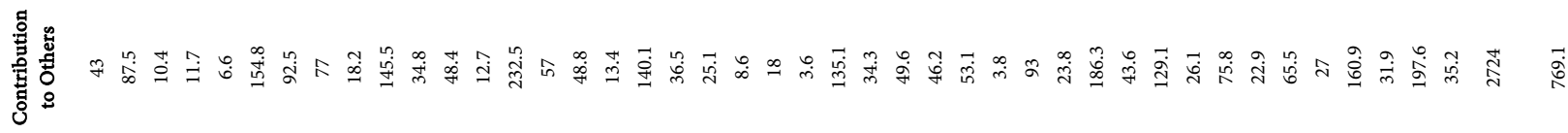

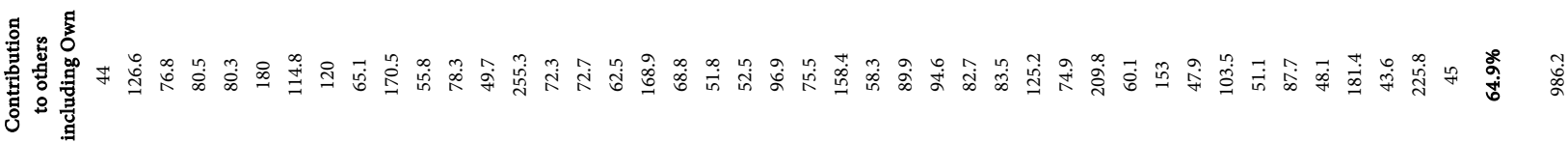

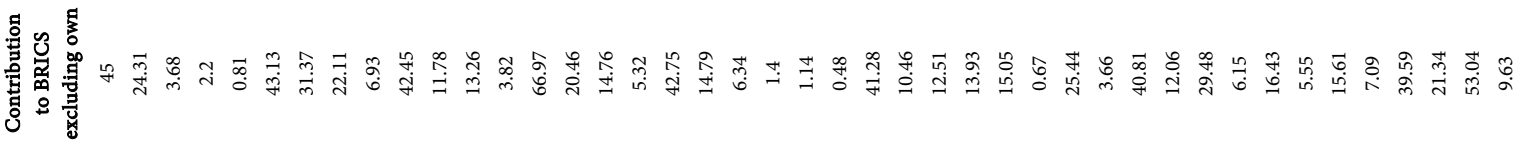

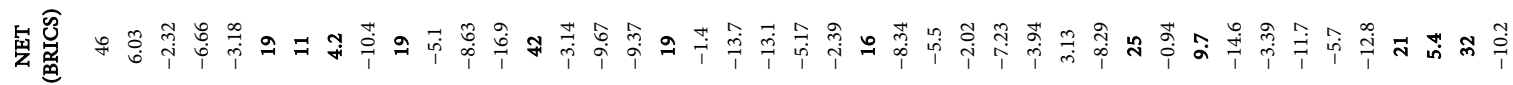

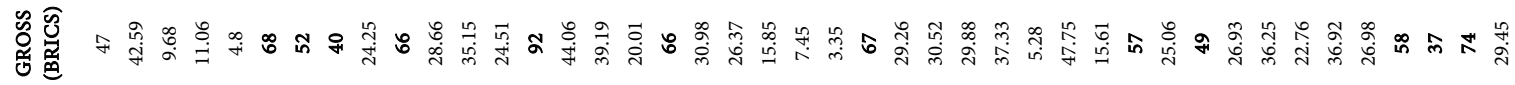

Notes: i) Diebold and Yilmaz [2] spillover index methodology is used for return and conditional volatility of 20 sample markets along with US as a global factor giving a $42 \times 42$ connectedness matrix representing the linkages across the two moments of each market (Row $1-42$, Column 1 - 42). All values are measured in percentage. Each Row sums to $100 \%$. "R" after each country represents return, "V" after each country represents volatility. ii) Contribution to Others (Row 43) shows the sum of spillovers from the given sample market to all other countries \& markets; iii) Contribution to others including own (Row 44) shows the sum of spillovers from the given sample market to own as well as all other countries; iv) Contribution to BRICS excluding own: (Row 45) shows the sum of spillovers from the given sample market to BRICS (excluding own market in case of BRICS); v) Contribution from Others (Column 43) shows the spillover from all other markets to the given sample market; vi) Contribution from BRICS excluding own (Column 44) shows the spillover from BRICS to the given sample market; vii) NET (BRICS) (Row 46): Row 45 - (Transpose: Column 44): Showing Dominance; viii) Gross (BRICS) (Row 47): Row 45 + (Transpose of Column 44): Showing Openness; ix) Volatility spillover index appears in the lower right corner of the Table.

The findings suggest that BRICS and Chile, Hungary, Mexico, Peru and Poland have substantial influence on one another as shown by high bidirectional return spillovers. With respect to volatility spillovers across BRICS, within own market spillovers are around 23\% except for South Africa for which it is 11\%. Examining pairwise volatility spillovers amongst BRICS and other EMEs with BRICS, Brazil-Chile, Brazil-Mexico, South Africa-Mexico, South Africa-Peru and South Africa-Poland are found to be relatively high. This indicates that Mexico, Brazil and South-Africa have substantial influence on one another exhibited by high bidirectional volatility spillovers. Analyzing the spillovers across return and volatility, the cross-interaction between risk and return is low as much of the interactions are within its own moment.

The sum of off-diagonal column elements in the matrix (Contribution to Others) or the sum of row (Contribution from Others), gives the numerator of Total Spillover Index when summed across countries. Similarly, the sum of column or sum of row including the diagonals, when aggregated across all countries, gives the denominator of Total Spillover Index. Total volatility spillover index is reflected at the lower right corner of Table 5. It is expressed in percentage terms. Total spillover index is at 64.90 percent which indicates that the interdependencies among the financial markets are high, as around $65 \%$ of the forecast errors come from spillovers. The spillover table exhibits an approximate "input-output" decomposition of total volatility spillover index. Table 5 
also displays Net and Gross Spillovers for all markets and as well as for BRICS. Column 43 of Table 5 labeled "contribution from others" sums the directional spillovers to market "I" from rest of the sample markets. The row 43 labeled "contribution to others" represents the directional spillover from market " $i$ " to other markets in the model. Similarly, Column 44 labeled "contribution from BRICS excluding own" sums the directional spillovers to market " $i$ " from BRICS markets and row 44 labeled "contribution to BRICS excluding own" represents the directional spillover from market "i" to BRICS markets in the model. Dominance of financial markets can be inferred by directional spillovers "to" and "from" other markets that are the two key aspects based on the combined effect. Dominance of a country's market can be established if it influences in transmitting information to other markets, but is relatively less influenced from them. Therefore, calculating and analyzing difference between "contribution to others" and "contribution from others" also known as net spillovers of the financial markets is an important tool to evaluate dominance/subordination of a given market. In addition, we estimate Gross spillover which is the sum of "contribution to others" and "contribution from others". Both Net and Gross spillovers have their own relevance in cross country interactions. Gross spillover can be a measure of enhanced linkages, thereby showing level of openness of a given financial market.

Since the study focuses on interactions between the BRICS economies, we wish to identify other EMEs which have strong interactions with BRICS based on equity market analysis and hence can be potential candidates that could be considered for expanding BRICS into a more comprehensive EME block. A similar computation for BRICS has been repeated. To find the markets having dominance over BRICS, we calculate the Net Spillover (BRICS) as the difference of contribution of the market to BRICS and Contribution to the market from BRICS. A positive value of Net contribution establishes dominance of market in transmitting information to BRICS. Gross Spillover (BRICS) refers to the sum of contribution of the market to BRICS and from BRICS. The rows 46 and 47 show these figures respectively. Analyzing the net spillover results, the authors find that within BRICS, Brazil, Russia and South Africa seem to be dominant markets based on return spillovers, while the latter (South Africa) is the only dominant market among the volatility spillovers shown by positive Net Spillover values for these countries. Among other EMEs, Argentina, Chile, Colombia, Hungary and Mexico returns dominate BRICS as per return spillovers, while Chile and Pakistan seem to be dominant viz-a-viz BRICS as per volatility spillovers. All these markets also exhibit higher level of openness as shown by large Gross Spillover Values for them.

\subsubsection{Block Aggregation Approach under Diebold-Yilmaz Results}

Greenwood-Nimmo et al. [3] have given a novel method in which block aggregation approach is used under Diebold-Yilmaz framework to integrate sets of individual variables for examining linkages among the group of variables. The 
block aggregation technique is utilized to capture the spillover effects that flow through return and volatility across the EMEs. Therefore, we aggregate first two moments by applying block aggregation routine to the $42 \times 42$ matrix presented in Table 5. This helps us to examine linkages among the emerging markets flowing through risk and return in a common framework providing a comprehensive picture to elucidate their interactions. Table 6 (Panel A) presents $21 \times$ 21 market connectedness matrix depicts the combined spillovers among the sample markets aggregated over the two moments (return and conditional volatility). As in case of Table 5, the diagonal elements of the matrix represent combined within market spillovers and off-diagonal elements represent cross-market spillovers. The within market spillover among BRICS range from $20.85 \%$ for

Table 6. Block aggregation approach under Diebold-Yilmaz (Equity Market Results).

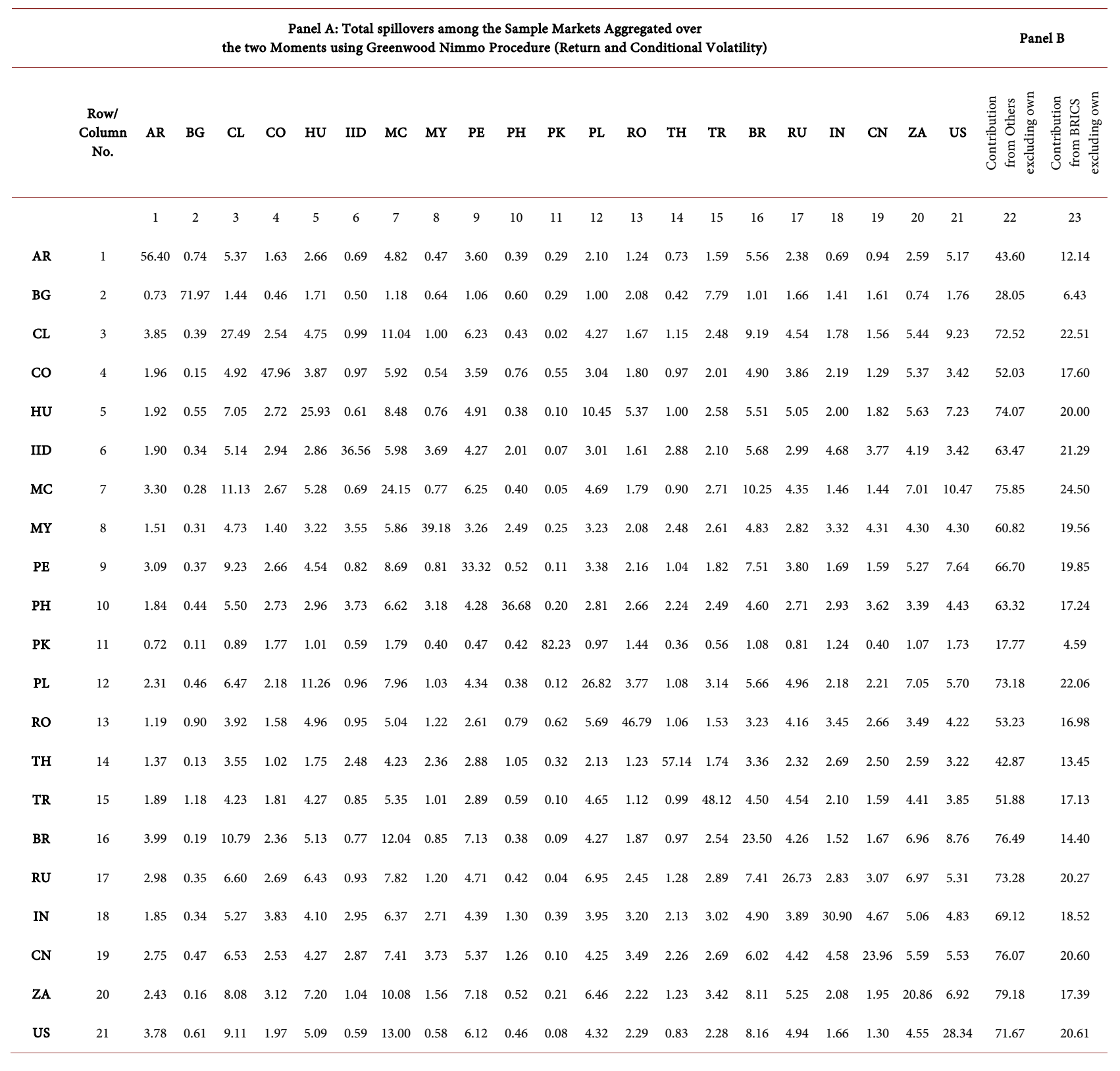




\section{Continued}

Panel B: Net/Gross Spillovers to all Markets and Net/Gross Spillovers to BRICS

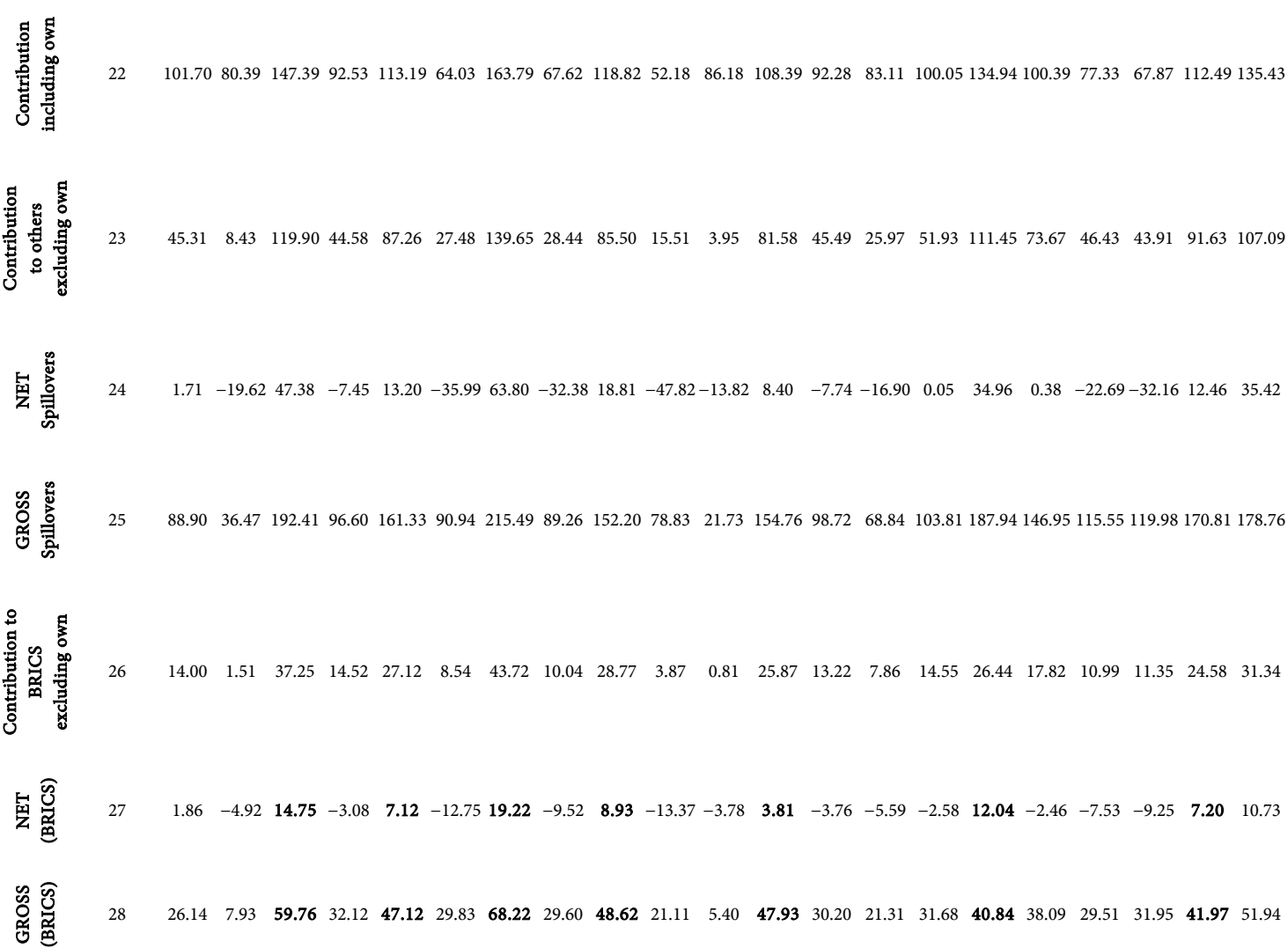

Notes: i) Greenwood-Nimmo et al. [3] block aggregation approach is used under Diebold-Yilmaz framework to integrate a set of individual variables to examine linkages of 20 sample markets (along with US as a global factor) giving a $21 \times 21$ connectedness matrix depicting the total spillovers among the sample markets aggregated over the two moments (return and conditional volatility). (Row 1 - 21, Column 1 - 21) All values are measured in percentage. Each Row sums to $100 \%$. ii) Contribution to others including own (Row 22) shows the sum of spillovers from the given sample market to own as well as all other countries; iii) Contribution to Others (Row 23) shows the sum of spillovers from the given sample market to all other countries \& markets; iv) Contribution from Others excluding own (Column 22) shows the spillover from all other markets to the given sample market; v) NET Contribution: Row 23 (Transpose of Column 22): Showing Dominance. (Row 24); vi) Gross Contribution: Row 23 + (Transpose of Column 22): Showing Openness. (Row 25); vii) Contribution to BRICS excluding own: (Row 26) shows the sum of spillovers from the given sample market to BRICS (excluding own market in case of BRICS); viii) Contribution from BRICS excluding own (Column 23) shows the spillover from BRICS to the given sample market; ix) NET (BRICS): Row 26 - (Column 23): Showing Dominance of the sample market over BRICS. (Row 27); x) Gross (BRICS): Row 26 + (Column 23): Showing Openness of the sample market with BRICS.(Row 28).

South Africa to $30.89 \%$ for India. Similar to Table 5, the sum of off-diagonal column elements in the matrix (Contribution to Others) or the sum of row (Contribution from Others), gives the numerator of Total Spillover Index when summed across countries. Similarly, the sum of column or sum of row including the diagonals, when aggregated across all countries, gives the denominator of Total Spillover Index as shown in the right corner of Table 6. It is expressed in percentage terms. Total spillover index is approximately 61 percent which indicates that the interdependencies among the markets are high as over $60 \%$ of the forecast errors come from spillovers. Table 6 (Panel B) displays Net and Gross Spillovers for all markets and as well as for BRICS computed separately as done in Table 5. Russia, India and China are the net receivers of total spillovers, 
meaning that the information arising from Brazil and South Africa have spillover implications for Russia, India and China. Brazil and South Africa are net transmitters of information to the other members of BRICS which is shown by positive Net (BRICS) Contribution (Row 27). Countries namely Chile, Hungary, Mexico, Peru and Poland have a positive Net contribution and also a high value of Gross contribution. High value of Gross contribution of these markets also reflects higher level of Globalization/Openness (Row 28).

\subsubsection{Rolling-Sample Analysis: Time Varying Spillover Results}

The static spillover results are supplemented with rolling window analysis to capture the time-varying characteristics of the spillover indices. We present results with $h=10$ days and a rolling window of 250 days. Figure 2 depicts dynamic total spillover index for all sample emerging markets using 250 day rolling window for estimation and 10 day forecast period. The shaded area presents the crisis period. We notice increase in spillover effect since 2005 and then a steep fall in 2012. The time varying evolution of Gross and Net spillovers of BRICS along with Chile, Hungary, Mexico, Peru and Poland with all the sample EMEs including BRICS is presented in Figure 3 and Figure 4 respectively. Figures (a) to (e) represent BRICS, (f) to (j) represent EMEs (reported only for those EMEs that have high Gross Spillover (BRICS) values and a positive NET Spillover (BRICS)). Highlighted portion marks the crisis period. As stated earlier, a positive NET contribution means that the market is able to influence in transmitting information to EMEs including BRICS, but is relatively less influenced by EMEs including BRICS. Countries namely Brazil, South-Africa, Chile, Hungary and Mexico have high positive NET contributions throughout the

\section{Total Spillovers}

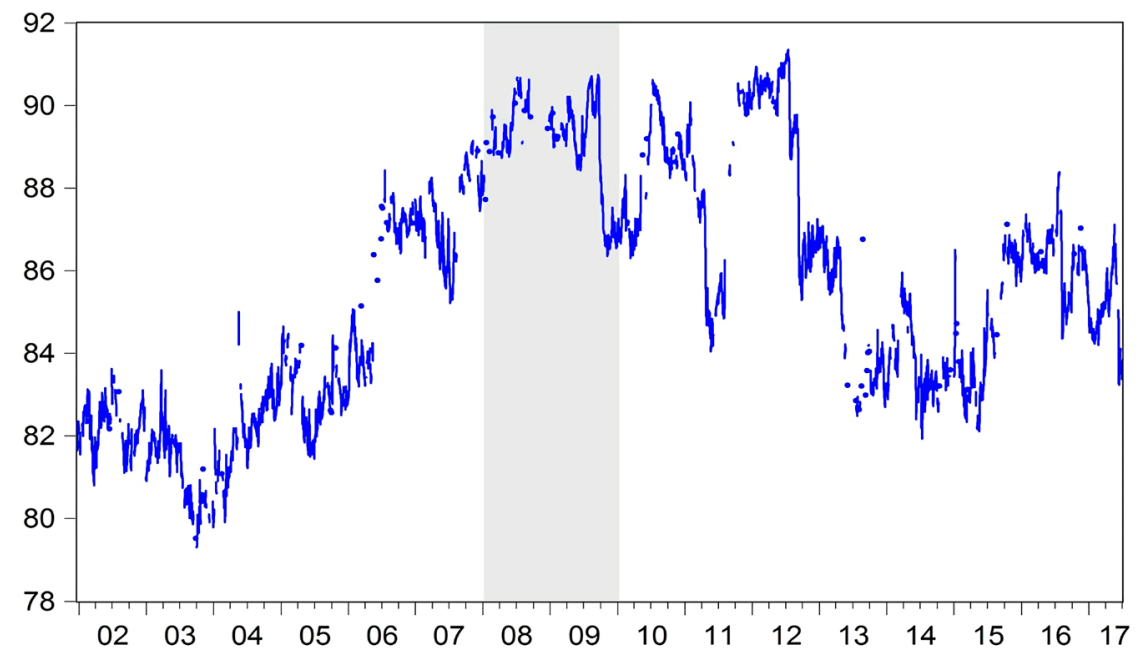

Figure 2. Dynamic total spillovers for all the sample equity EMEs. Notes: i) The graph in the figure shows Dynamic Total Spillovers for all the sample EMEs including BRICS for the entire period of study; ii) Dynamic spillover index is obtained using 250 day rolling window for estimation and 10 day forecast period; iii) Crisis period is highlighted, reflected by the shaded region; iv) $x$-axis represents: Year, $y$-axis represents: Total Spillover (\%). 

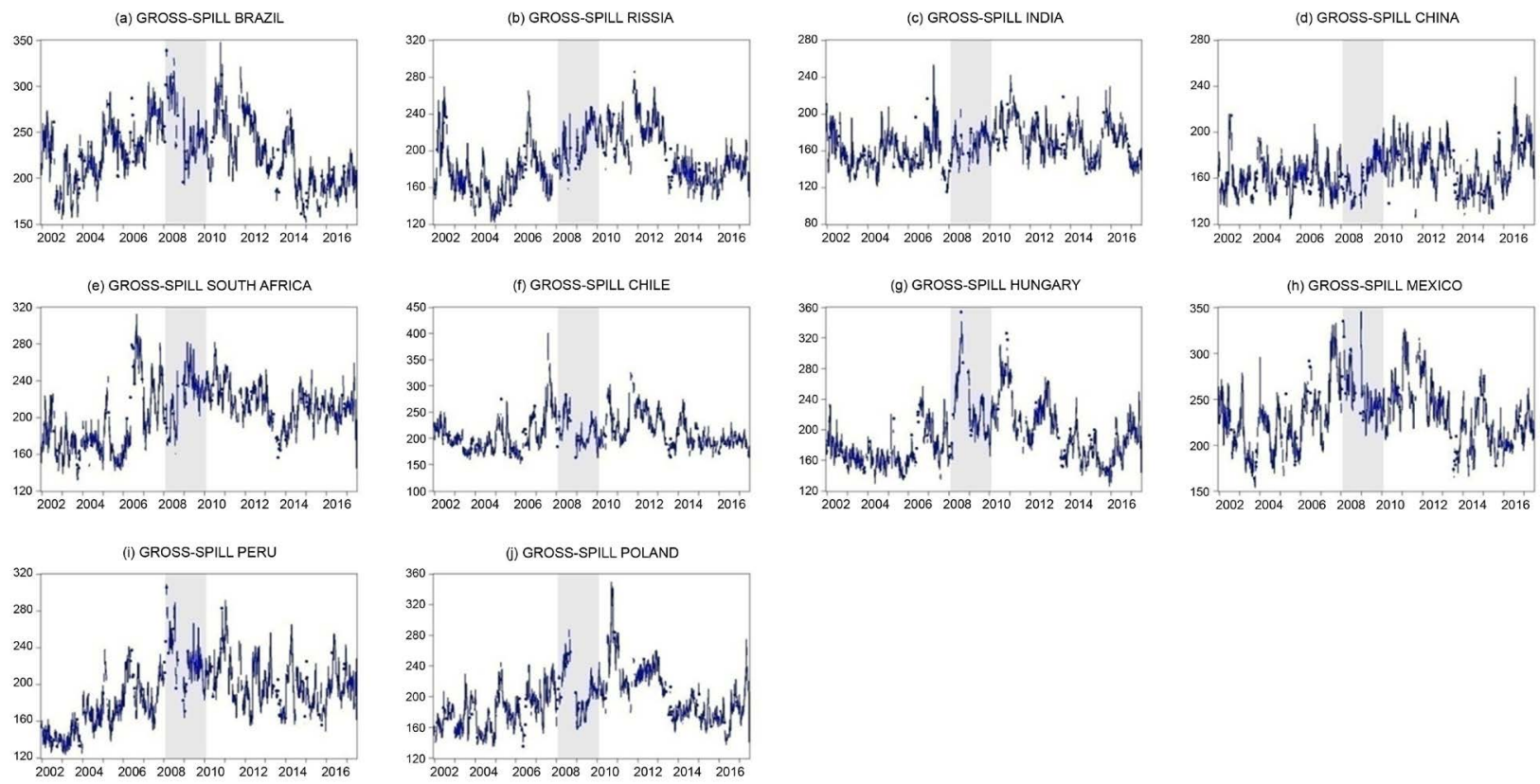

Figure 3. Dynamic gross spillovers for select equity EMEs including BRICS. Notes: i) The graphs in the figure show Dynamic Gross Spillovers for only those EME that have high Gross Spillover (BRICS) values and a positive NET Spillover (BRICS) with all the sample EMEs including BRICS for the entire period of study; ii) Graphs from (a) to (e) represent BRICS, (f) to (j) represent Chile, Hungary, Mexico, Peru and Poland respectively; iii) Dynamic spillover index is obtained using 250 day rolling window for estimation and 10 day forecast period; iv) Crisis period has also been highlighted, reflected by the shaded region in each graph; v) $\mathrm{x}$-axis represents: Year, $\mathrm{y}$-axis represents: Gross Spillover (\%).
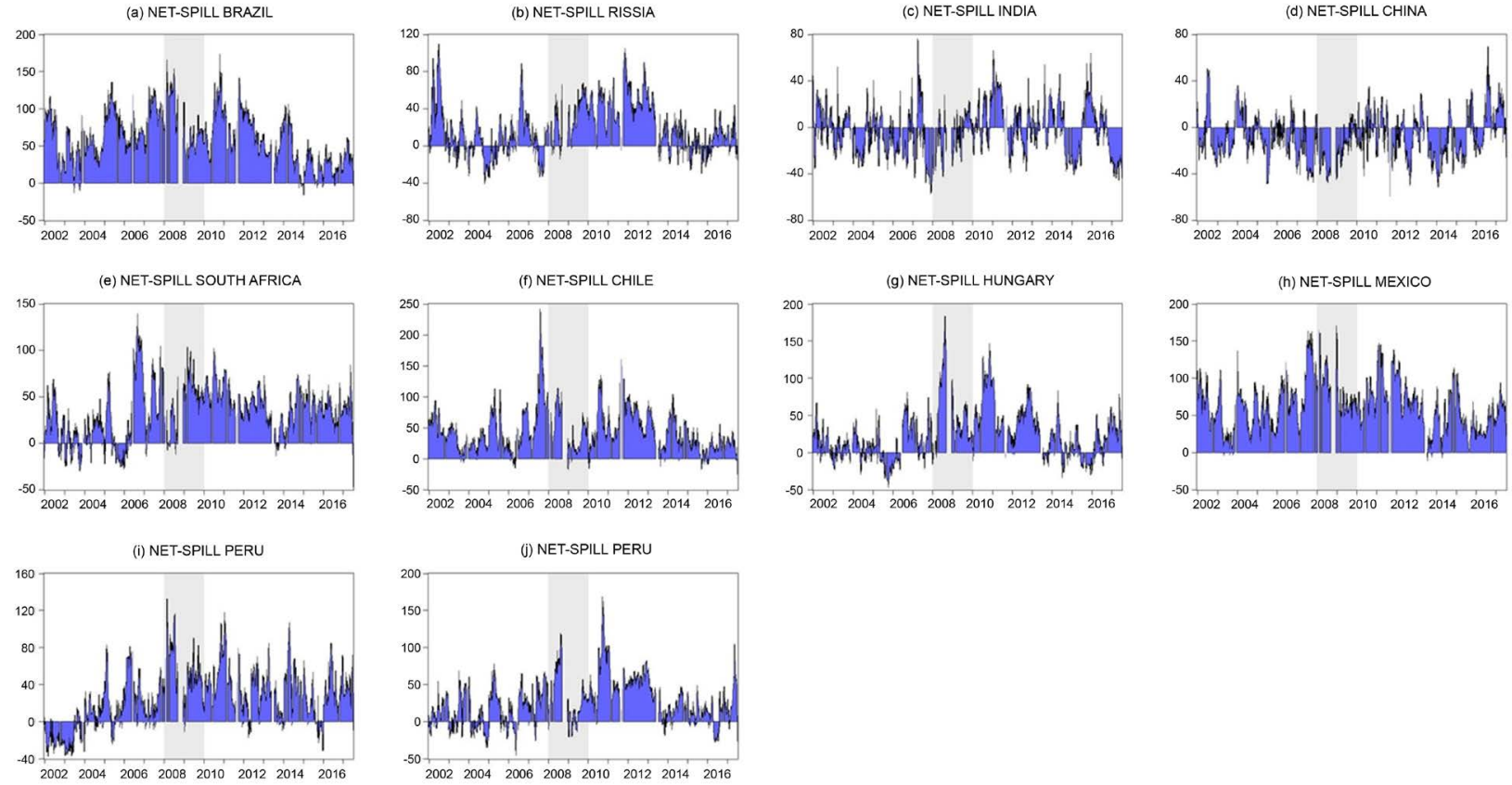

Figure 4. Dynamic net spillovers for select equity EMEs including BRICS. Notes: i) The graphs in the figure show Dynamic Net Spillovers for only those EME that have high Gross Spillover (BRICS) values and a positive NET Spillover (BRICS) with all the sample EMEs including BRICS for the entire period of study; ii) Figures (a) to (e) represent BRICS, (f) to (j) represent Chile, Hungary, Mexico, Peru and Poland respectively; iii) Dynamic spillover index is obtained using 250 day rolling window for estimation and 10 day forecast period; iv) Crisis period has also been highlighted reflected by the shaded region in each graph; v) $\mathrm{x}$-axis represents: Year, $\mathrm{y}$-axis represents: Net Spillover (\%). 
sample period. As mentioned earlier, Gross spillover shows level of openness and Net spillovers show dominance.

\section{Summary, Conclusion and Policy Implications}

\subsection{Summary and Key Findings}

In this paper, dynamic interactions between BRICS (Brazil, Russia, India, China and South Africa) and other EMEs over the period January 2001 to June 2017 is investigated. The data comprises of daily values of MSCI stock price indices for the stated 23 Emerging Markets Economies as provided by IMF 2015 list [1]. However, Bangladesh, Ukraine and Venezuela have been excluded from the study due to lack of availability of sufficient data, finally covering 20 emerging markets including BRICS. Data for US has been included additionally as a proxy for Global market factor. Using appropriate econometric techniques, it is found that within BRICS, South Africa has the highest association with other members of the block and India has the lowest association with other members. With respect to other emerging economies Chile, Mexico and Poland exhibit higher association with BRICS as compared to BRICS average, with Hungary and Turkey being close to the average. Further, it was found that South Africa and Brazil dominate other BRICS members. Associations in the group and other select EMEs seem to have increased during the crisis and post-crisis period but this may reflect contagion.

Based on prior research work; fiscal position, stock market performance, trade linkages were some factors that were identified as key drivers of equity market integration. It will further be interesting to study emerging economies on similar framework. Most of BRICS economies have wide differences in their economic indicators. Among the macro-economic factors, current account balance (as a percent of GDP) in China and Russia has stayed positive and in Brazil, India and South Africa ranged between $-0.6 \%$ to $-5.9 \%$ during the study period. This reveals that all BRICS countries do not have a similar current account position, which may result in a lower level of integration as compared to other blocks in the developed world. Among the trade factors, over the period of study, BRICS has emerged as a key player of global trade. Between 2001 and 2015, the contribution of BRICS in imports and exports worldwide increased from $7 \%$ to $15 \%$ and $8 \%$ to $18 \%$, respectively. Overall BRICS global trade increased over six times during the period. Throughout these years, BRICS as a group witnessed trade surplus with all other economies of the world that stood at around US $\$ 640$ billion in 2015. While the group's trade with the rest of the world shows a strong upward trend between 2001 and 2016, it, however, suffered two small setbacks following the global financial crisis in 2008 and the drop in global commodity prices in 2014.

\subsection{Conclusion}

Based on the findings of this paper, it is advisable to extend the BRICS into a 
broader and more relevant block as "Emerging Market Economic Community" including Mexico, Chile, Poland, Hungary and Turkey. The new block will account for a much wider market, with Brazil, Mexico and Chile representing the emerging markets in South America. Mexico is one of the most looked after countries in Latin America and is also a member of NAFTA. Further Mexico's mixed blessing of sharing its border with US can prove to be an important member of the group. China, Russia and India represent Asia. South Africa is the strongest economy in the African continent. Hungary, Poland and Turkey represent the chief emerging economies in Europe. Turkey is also regarded as a gateway to Middle East. Turkey's strategic location between Europe, Middle East and Central Asia and its fast modernizing and industrializing economy will increase the group's influence in Europe and Middle East.

\subsection{Policy Implications}

The study has important implications for policy makers, international economic agencies, investors and academia. For policy makers around the globe, the study is of particular relevance as it suggests expanding the existing economic block by including Mexico, Chile, Poland, Hungary and Turkey. The expanded block will be more capable in achieving political influence, enhanced economic and trade linkages amongst economies as well as developing a coordinated response to global risks including financial contagion. For international economic agencies like World Bank and International Monetary fund the setting up of New Development Bank by BRICS will challenge the monopoly of these institutions by providing alternative sources of finance at ease to the emerging economies. Inclusion of new members will increase the bank capital base and ease the problems faced by emerging economies in procuring finance. The proposed group shall be a combination of heterogeneous markets and for investors, this expanded group will provide risk diversification opportunities as the block currently exhibits relatively low correlations as compared to developed economies. The expanded block will also be able to compete with the G7 economies in the near future, thereby challenging their influence in the world economic order and international institutions. This proposed group can emerge as the new growth engine of the world and provide balance in economic power between the developed and the developing world. For academic community, this paper is useful in better understanding of the information linkages between the geographically dispersed economic block with member counties exhibiting different political and cultural environment. The study contributes to the existing literature by examining candidacy of EMEs and the possibility of expanding the existing block to form "Emerging Markets Economic Community" as a more viable Emerging Market Block in the future.

\section{Conflicts of Interest}

The authors declare no conflicts of interest regarding the publication of this paper. 


\section{References}

[1] IMF (2015) World Economic Outlook: Adjusting to Lower Commodity Prices. https://www.imf.org/external/pubs/ft/weo/2015/02/pdf/text.pdf

[2] Diebold, F.X. and Yilmaz, K. (2012) Better to Give than to Receive : Predictive Directional Measurement of Volatility Spillovers. International Journal of Forecasting, 28, 57-66. https://doi.org/10.1016/j.ijforecast.2011.02.006

[3] Greenwood-Nimmo, M., Nguyen, V.H. and Rafferty, B. (2016) Risk and Return Spillovers among the G10 Currencies. Journal of Financial Markets, 31, 43-62. https://doi.org/10.1016/j.finmar.2016.05.001

[4] Agénor, P. (2003) Benefits and Costs of International Financial Integration: Theory and Facts. The World Economy, 26, 1089-1118. https://doi.org/10.1111/1467-9701.00564

[5] Fahami, N.A. (2011) The Structure of Linkages and Causal Relationships between BRIC and Developed Equity Markets. International Conference on Information and Finance, 21, 72-77.

[6] Worthington, A. and Higgs, H. (2010) Assessing Financial Integration in the European Union Equity Markets: Panel Unit Root and Multivariate Cointegration and Causality Evidence. Journal of Economic Integration, 25, 457-479. https://doi.org/10.11130/jei.2010.25.3.457

[7] MSCI (2016) Thinking Broadly about Emerging Markets. MSCI.

[8] Lagarde, C. (2016) The Role of Emerging Markets in a New Global Partnership for Growth by IMF Managing Director Christine Lagarde. IMF, 401. http://www.imf.org/external/np/speeches/2016/020416.htm

[9] Sperlich, Y. (2015) From Power Transition to Economic Integration Theory: A Review of the BRICS Literature Yvonne Sperlich from Power Transition to Economic Integration Theory: A Review of the BRICS Literature. Geneva School of Economics and Management, Working Paper Series. https://doi.org/10.2139/ssrn.2671421

[10] Leme, P., Potter, S., Walton, D. and Neill, J.O. (2002) Building Better Global Economic BRICs. Goldman Sachs Economic Research Group Jim, 1-16.

[11] Yavuz, M. and Kabundi, A. (2013) Trade Shocks from BRIC to South Africa: A Global VAR Analysis. Economic Modelling, 32, 190-202. https://doi.org/10.1016/j.econmod.2013.02.010

[12] Çakir, M. (2013) South Africa's Economic Integration with BRIC Countries.

[13] Manning, J. (2014) Can the BRICS New Development Bank Compete with the World Bank and the IMF?

http://internationalbanker.com/banking/can-brics-new-development-bank-compet e-world-bank-imf/

[14] Luna, V.M.I. (2016) Brics' Bank: Possibilities and Constraints. Economía Informa, 398, 3-22. https://doi.org/10.1016/j.ecin.2016.04.002

[15] Phylaktis, K. and Ravazzolo, F. (2002) Measuring Financial and Economic Intergration with Equity Prices in Emerging Markets. Journal of International Money and Finance, 21, 879-903. https://doi.org/10.1016/S0261-5606(02)00027-X

[16] Sehgal, S., Pandey, P. and Deisting, F. (2017) Stock Market Integration Dynamics and its Determinants in the East Asian Economic Community Region. Journal of Quantitative Economics, 16, 389-425. https://doi.org/10.1007/s40953-017-0090-7

[17] Visalakshmi, S. and Lakshmi, P. (2016) BRICS Market Nexus for Cross Listed Stocks: A VECX Framework. The Journal of Finance and Data Science, 2, 76-88. https://doi.org/10.1016/j.jfds.2016.02.001 
[18] Bhar, R. and Nikolova, B. (2009) Return, Volatility Spillovers and Dynamic Correlation in the BRIC Equity Markets : An Analysis Using a Bivariate EGARCH Framework. Global Finance Journal, 19, 203-218. https://doi.org/10.1016/j.gfj.2008.09.005

[19] Sheu, H.-J. and Liao, C.-H. (2011) Dynamics of Stock Market Integration between the US and the BRIC. African Journal of Business Management, 5, 3674-3689.

[20] Xu, H. and Hamori, S. (2012) Dynamic Linkages of Stock Prices between the BRICs and the United States: Effects of the 2008-09 Financial Crisis. Journal of Asian Economics, 23, 344-352. https://doi.org/10.1016/j.asieco.2012.04.002

[21] Ahmad, W., Sehgal, S. and Bhanumurthy, N.R. (2013) Eurozone Crisis and BRIICKS Stock Markets : Contagion or Market Interdependence? Economic Modelling, 33, 209-225. https://doi.org/10.1016/j.econmod.2013.04.009

[22] Gabriela, I., Panait, M. and Voica, C. (2014) BRICS Countries Challenge to the World Economy New Trends. Procedia Economics and Finance, 8, 605-613. https://doi.org/10.1016/S2212-5671(14)00135-X

[23] Chen, L. and De Lombaerde, P. (2014) Testing the Relationships between Globalization, Regionalization and the Regional Hubness of the BRICs. Journal of Policy Modeling, 36, S111-S131. https://doi.org/10.1016/j.jpolmod.2013.10.011

[24] Gilenko, E. and Fedorova, E. (2014) Research in International Business and Finance Internal and External Spillover Effects for the BRIC Countries: Multivariate GARCH-in-Mean Approach. Research in International Business and Finance, 31, 32-45. https://doi.org/10.1016/j.ribaf.2013.11.002

[25] Jawadi, F., Mallick, S.K. and Sousa, R.M. (2015) Fiscal and Monetary Policies in the BRICS : A Panel VAR Approach. Economic Modelling, 58, 535-542. https://doi.org/10.1016/j.econmod.2015.06.001

[26] Syriopoulos, T., Makram, B. and Boubaker, A. (2015) International Review of Financial Analysis Stock Market Volatility Spillovers and Portfolio Hedging: BRICS and the Financial Crisis. International Review of Financial Analysis, 39, 7-18. https://doi.org/10.1016/j.irfa.2015.01.015

[27] Nashier, T. (2015) Financial Integration between BRICS and Developed Stock Markets Tripti Nashier. International Journal of Business and Management Invention, 4, 65-71.

[28] Kan, K. (2015) Has BRICS Countries Decoupled from the Effect of Contagion during the 2008 Financial Crisis? Comparison of VECM Model and DCC GARCH Model. Proceedings of 4th European Business Research Conference, Imperial College, London, 9-10 April 2015.

[29] Singh, A. and Singh, M. (2016) Inter-Linkages and Causal Relationships between US and BRIC Equity Markets: An Empirical Investigation. Arab Economic and Business Journal, 11, 115-145. https://doi.org/10.1016/j.aebj.2016.10.003

[30] Robbani, M.G., Talukdar, B. and Jain, A. (2016) Information Transmission and Dynamics of Stock Price Movements: An Empirical Analysis of BRICS and US Stock Markets. International Review of Economics and Finance, 46, 180-195. https://doi.org/10.1016/j.iref.2016.09.004

[31] Mensi, W., Hammoudeh, S. and Hoon, S. (2017) Dynamic Linkages between Developed and BRICS Stock Markets : Portfolio Risk Analysis. Finance Research Letters, 21, 26-33. https://doi.org/10.1016/j.frl.2016.11.016

[32] Bonga-Bonga, L. (2018) Uncovering Equity Market Contagion among BRICS Countries: An Application of the Multivariate GARCH Model. Quarterly Review of Economics and Finance, 67, 36-44. https://doi.org/10.1016/j.qref.2017.04.009

[33] Aggarwal, R. and Kyaw, N.A. (2005) Equity Market Integration in the NAFTA Re- 
gion: Evidence from Unit Root and Cointegration Tests. International Review of Financial Analysis, 14, 393-406. https://doi.org/10.1016/j.irfa.2004.10.008

[34] Ciner, C. (2006) A Further Look at Linkages between NAFTA Equity Markets. The Quarterly Review of Economics and Finance, 46, 338-352.

https://doi.org/10.1016/j.qref.2006.02.007

[35] Lahrech, A. and Sylwester, K. (2013) The Impact of NAFTA on North American Stock Market Linkages. The North American Journal of Economics and Finance, 25, 94-108. https://doi.org/10.1016/j.najef.2013.04.001

[36] Assaf, A. (2015) Value-at-Risk Analysis in the MENA Equity Markets: Fat Tails and Conditional Asymmetries in Return Distributions. Journal of Multinational Financial Management, 29, 30-45. https://doi.org/10.1016/j.mulfin.2014.11.002

[37] Assaf, A. (2016) MENA Stock Market Volatility Persistence: Evidence before and after the Financial Crisis of 2008. Research in International Business and Finance, 36, 222-240. https://doi.org/10.1016/j.ribaf.2015.09.003

[38] Garali, W. and Othmani, S. (2015) The Determinants of International Financial Integration in the MENA Area. Procedia Economics and Finance, 26, 535-541. https://doi.org/10.1016/S2212-5671(15)00951-X

[39] Cappiello, L., Engle, R.F. and Sheppard, K. (2006) Asymmetric Dynamics in the Correlations of Global Equity and Bond Returns. Journal of Financial Econometrics, 4, 537-572. https://doi.org/10.1093/jjfinec/nbl005

[40] Plummer, M.G. (2006) ASEAN-EU Economic Relationship: Integration and Lessons for the ASEAN Economic Community. Journal of Asian Economics, 17, 427-447. https://doi.org/10.1016/j.asieco.2006.04.004

[41] Sehgal, S. and Gupta, P. (2016) Time Varying Integration in EMU's Retail Banking to Non-Financial Corporations. Journal of Economic Integration, 31, 674-735. https://doi.org/10.11130/jei.2016.31.3.674

[42] Sehgal, S., Gupta, P. and Deisting, F. (2017) Assessing Time-Varying Stock Market Integration in Economic and Monetary Union for Normal and Crisis Periods. European Journal of Finance, 23, 1025-1058. https://doi.org/10.1080/1351847X.2016.1158727

[43] Tang, D. (2016) Has the Financial Integration Affected the European Union (EU) Trade with the New Member Countries from Central and Eastern Europe (CEEC) during 1994-2013? The Journal of Economic Asymmetries, 13, 8-20. https://doi.org/10.1016/j.jeca.2015.10.004

[44] Lyocsa, S. and Baumohl, E. (2015) Similarity of Emerging Market Returns under Changing Market Conditions: Markets in the ASEAN-4, Latin America, Middle East, and BRICs. Economic Systems, 39, 253-268.

https://doi.org/10.1016/j.ecosys.2014.08.001

[45] Dua, P. and Tuteja, D. (2016) Financial Crises and Dynamic Linkages across International Stock and Currency Markets. Economic Modelling, 59, 249-261. https://doi.org/10.1016/j.econmod.2016.07.013

[46] Kim, M.H. and Sun, L. (2017) Dynamic Conditional Correlations between Chinese Sector Returns and the S \& P 500 Index: An Interpretation Based on Investment Shocks. International Review of Economics and Finance, 48, 309-325. https://doi.org/10.1016/j.iref.2016.12.014

[47] Sugimoto, K., Matsuki, T. and Yoshida, Y. (2014) The Global Financial Crisis: An Analysis of the Spillover Effects on African Stock Markets. Emerging Markets Review, 21, 201-233. https://doi.org/10.1016/j.ememar.2014.09.004

[48] Forbes, K.J. and Rigobon, R. (2002) No Contagion, Only Interdependence: Mea- 
srung Stock Market Comovements. The Journal of Finance, 57, 2223-2261. https://doi.org/10.3386/w7267

[49] Baumohl, E. (2013) Stock Market Integration between the CEE-4 and the G7 Markets: Asymmetric DCC and Smooth Transition Approach. Eduard. Munich Personal RePEc Archive.

[50] Nelson, D.B. (1991) Conditional Heteroskedasticity in Asset Returns: A New Approach. Econometrica, 59, 347-370. https://doi.org/10.2307/2938260

https://www.jstor.org/stable/2938260?seq=1\#page_scan_tab_contents 